\title{
La dimensión constitucional y convencional del derecho a la tutela judicial efectiva (no penal) desde la perspectiva jurisprudencial europea y americana
}

The constitutional and conventional dimension of the right to effective (non-criminal) judicial protection from the european and american jurisprudential perspective

\author{
Benjamin MARCheco AcuÑa ${ }^{1}$ \\ Universidad de Guayaquil \\ benjamarcheco@gmail.com
}

\begin{abstract}
Resumen: El derecho fundamental a la tutela judicial efectiva ha devenido un concepto clave en el desarrollo del constitucionalismo y del derecho internacional de los derechos humanos a partir de la segunda mitad del siglo pasado. La construcción y consolidación teórica de su contenido ha sido producto de un largo, depurado y aún no acabado desarrollo jurisprudencial en el que ha sido esencial el dialogo interinstitucional entre los
\end{abstract}

1 Doctor en Ciencias Jurídicas (Universidad de La Habana), Master en Especialización e Investigación en Derecho *Universidad de Zaragoza), Master en Derecho Constitucional (Universidad Internacional Menéndez Pelayo), Master en Derecho Constituciona y Administrativo (Universidad de La Habana). Profesor de la Facultad de Jurisprudencia y Ciencias Sociales y Políticas de la Universidad de Guayaquill, Ecuador. 
tribunales internacionales de derechos humanos y las cortes y tribunales nacionales. El presente trabajo pretende sistematizar, sin ánimos de exhaustividad, los principales aspectos teóricos del derecho fundamental a la tutela judicial efectiva en el ámbito no penal desde una perspectiva comparada, en Europa y América, sobre la base de la jurisprudencia desarrollada por los principales tribunales internacionales de derechos humanos: el Tribunal Europeo (TEDH) y la Corte Interamericana (Corte IDH) y de algunas cortes o tribunales constitucionales de ambas regiones, con el que se pretende contribuir a una mejor comprensión, interpretación y aplicación de dicho concepto.

Palabras clave: Tutela judicial efectiva, debido proceso, acceso a la justicia, derechos humanos, derechos fundamentales.

Abstract: The fundamental right to effective judicial protection has become a key concept in the development of constitutional law and international human rights law, starting in the second half of the last century. The theoretical construction and consolidation of its content has been the product of a long, refined and not yet finished jurisprudential development in which the inter-institutional dialogue between international human rights courts and national courts and tribunals has been essential. This work aims to systematize - without wishing to be exhaustive, the main theoretical aspects of the fundamental right to effective judicial protection in the non-criminal sphere, from a comparative perspective, in Europe and America, on the basis of the jurisprudence developed by the main international human rights courts: the European Court $(E C H R)$ and the Inter-American Court (I / A Court HR) and of some constitutional courts or tribunals of both regions; that can contribute to a better understanding, interpretation and application of this concept.

Keywords: Effective judicial protection, due process of law, access to justice, human rights, fundamental rights. 


\section{Introducción}

La tutela judicial efectiva es uno de esos conceptos claves sobre los que ha girado el desarrollo del constitucionalismo y del derecho internacional de los derechos humanos a partir de la segunda mitad del siglo pasado. Como derecho fundamental a nivel constitucional aparece en Europa tras la Segunda Guerra Mundial como "vigorosa reacción frente a la trágica experiencia jurídica de la época inmediatamente anterior al conflicto mundial, con las que las constituciones pretendieron frenar los embates del poder público en los dos frentes más amenazados: en materia penal y contencioso administrativa; convirtiéndose este derecho hoy en el centro de la dogmática del derecho público."2

Su origen se sitúa en la Constitución italiana de 1947 (art. 24), incorporada luego a la Grundgesetz alemana de 1949 (art. 19.4), aunque con esa denominación -con la cualidad añadida de "tutela efectiva"-, es producto del constituyente español de 1978 (art. 24.1) y así recogida luego en algunas de constituciones latinoamericanas más actuales como Venezuela (1999, art. 26); Ecuador (2008, arts. 11.9 y 75); Bolivia (2009, art. 115.1) y Cuba (2019, art. 92)

En el ámbito de los tratados internacionales de los derechos humanos, el término viene a recogerse por primera vez en la Carta de los Derechos Fundamentales de la Unión Europea de Niza, en 2000, que reconoce expresamente en su art. 47, el "derecho a la tutela judicial efectiva y a un juez imparcial" aunque, con terminologías diferentes, ya formaba parte del catálogo de derechos de Declaración Universal de los Derechos Humanos de 1948, -que consagra (art. 10) "el derecho de toda persona a ser oída, en condiciones de igualdad públicamente y con justicia por un tribunal imparcial e independiente para la determinación de sus derechos u obligaciones" y (art. 8), el derecho "a disponer de un recurso efectivo ante los tribunales nacionales que la ampare contra actos que violen sus derechos fundamentales reconocidos por la Constitución o por la ley." Con fórmulas análogas se recoge también el Pacto Internacional de los

2 BARNÉS (1993), pp. 136-139 
Derechos Civiles y Políticos de 1966 (art. 14); el Convenio Europeo para la Protección de los Derechos Humanos y de las Libertades Fundamentales de 1950, (art. 13), la Convención Americana sobre Derechos Humanos de San José, 1969 (art. 8.1 y 25) y la Carta Africana sobre Derechos Humanos y de los Pueblos de 1981(art. 7).

El derecho a la tutela judicial efectiva, que pudiéramos definir, siguiendo a DiEZ PICAZO, como aquel que se le reconoce a toda persona de acudir a los órganos jurisdiccionales para obtener, por el debido cauce procesal, una decisión fundada en derecho sobre las pretensiones deducidas respecto de sus derechos o legítimos intereses, esto es, que "cualesquiera situaciones jurídicas relevantes pueda ser, llegado el caso, defendidas ante un genuino órgano jurisdiccional, de manera que no existan supuestos de denegación de justicia"; 3 posee un contenido amplio, integrado por un complejo sistema de garantías para el ciudadano que se despliegan en tres momentos distintos: al acceder a la jurisdicción, durante el proceso y en la ejecución de la sentencia.

La proyección de este derecho fundamental adquiere especial relevancia en los procesos que se siguen contra las actuaciones de los poderes públicos, en tanto se trata de un "derecho instrumental" contra la vulneración de los demás derechos fundamentales, sin el cual estos mermarían enormemente su eficacia; ${ }^{4}$ pero es lo cierto que muchas veces se ha visto limitado por la sustracción al control jurisdiccional de ciertas zonas de inmunidad reservadas en exclusiva a la Administración pública que han impedido, por ello, la posibilidad de deducir pretensiones contra determinados comportamientos del poder público atentatorios contra la esfera jurídica individual reconocida por el ordenamiento.

La construcción y consolidación teórica del derecho a la tutela judicial efectiva, que pretende ir solucionando esas permanentes tensiones entre los derechos del individuo y el ejercicio del poder ${ }^{5}$, es producto de un largo, depurado y aún no acabado desarrollo jurisprudencial en el que ha

3 Diez Picazo (2008), p. 425.

4 Del Real (2020), p. 21.

5 MARCHeCo (2017), p. 25 
sido esencial el dialogo interinstitucional entre los tribunales internacionales de derechos humanos y las cortes y tribunales nacionales.

El presente trabajo pretende sistematizar, sin ánimos de exhaustividad, los principales aspectos teóricos del derecho fundamental a la tutela judicial efectiva en el ámbito no penal, desde una perspectiva comparada en Europa y América, sobre la base de la jurisprudencia desarrollada por los principales tribunales internacionales de derechos humanos: el Tribunal Europeo (TEDH) y la Corte Interamericana (Corte IDH) y de algunas cortes o tribunales constitucionales de ambas regiones, al propósito de contribuir a una mejor comprensión, interpretación y aplicación de dicho concepto.

\section{El derecho a la tutela judicial efectiva. Concepto}

La tutela judicial efectiva significa, para cualquier titular de alguna situación jurídica subjetiva, la posibilidad de deducir ante los órganos jurisdiccionales las pretensiones necesarias para defensa y protección de sus derechos e intereses legítimos frente a cualquier conducta o actuación que pudiera lesionarlos o desconocerlos y obtener una resolución de fondo ajustada a Derecho y su correspondiente ejecución, de conformidad con el ordenamiento jurídico sustantivo y procesal. Su reconocimiento dentro de la sistemática constitucional como una "garantía" ha de suponer, como primera consecuencia, la adaptación de las normas procesales a fin de que puedan proporcionar las vías idóneas para asegurar la plenitud de la defensa jurisdiccional de cualesquiera de las relaciones jurídico- materiales, sin que queden espacios de inmunidad o situaciones de indefensión.

En expresión de la Corte Interamericana de Derechos Humanos (Corte IDH), la existencia de un derecho a la tutela judicial efectiva implica la obligación de los Estados de garantizar un recurso judicial efectivo contra actos que violen derechos fundamentales; obligación que no se reduce simplemente a la mera existencia de los tribunales o procedimientos formales o aún a la posibilidad de recurrir a los tribunales, sino además al deber de adoptar medidas positivas para garantizar que los recursos que 
proporciona a través del sistema judicial sean "verdaderamente efectivos" para establecer si ha habido o no una violación a los derechos humanos y para proporcionar una reparación"6.

Un recurso efectivo, según la Corte IDH, sería el realmente idóneo para establecer si se ha incurrido en una violación a los derechos humanos y proveer lo necesario para remediarla, es decir, si ha contribuido efectivamente a poner fin a una situación violatoria de derechos, a asegurar la no repetición de los actos lesivos y a garantizar el libre y pleno ejercicio de los mismos. ${ }^{7}$ No pueden considerarse, en consecuencia, "efectivos", aquellos recursos que, por las condiciones generales del país o incluso por las circunstancias particulares de un caso dado resulten ilusorios; lo puede ocurrir, por ejemplo, cuando su inutilidad haya quedado demostrada por la práctica, porque el poder judicial carezca de la independencia necesaria para decidir con imparcialidad o porque falten los medios para ejecutar sus decisiones, o por cualquier otra situación que configure un cuadro de denegación de justicia, como sucede cuando se incurre en retardo injustificado en la decisión o, por cualquier causa, no se permita al presunto lesionado el acceso al recurso judicial. ${ }^{8}$

La tutela judicial efectiva es, por tanto, una garantía compleja, cuyo contenido se determina con base en otros derechos o garantías concretas, interdependientes unos de otros y que se pueden sintetizar en las siguientes:

a. derecho de acceso a la jurisdicción; esto es, a ser oído por un tribunal independiente e imparcial;

b. derecho al debido proceso; que implica la existencia de garantías mínimas tendentes a asegurar un resultado justo y que incluye el derecho a la defensa, a la igualdad de oportunidades, la equidad procesal y la utilización de los medios de impugnación;

c. derecho a una resolución de fondo, fundada en Derecho; que inclu-

6 CORTE IDH. Pueblo Indígena Kichwa de Sarayaku vs. Ecuador, párr. 261, 27/6/2012.

7 CORTE IDH. Forneron e hija vs. Argentina, párr. 108, 27/4/2012,

8 CORTE IDH. Opinión Consultiva OC-9/87, Garantías judiciales en estados de emergencia, párr. 24, $6 / 10 / 1987$. 
ye el control de la motivación de las resoluciones judiciales;

d. derecho a la tutela cautelar;

e. derecho a la ejecución.

\section{Titularidad}

La determinación de la titularidad del derecho a tutela judicial efectiva, según las diversas fórmulas con que se recoge en los instrumentos internacionales de derechos humanos a los que nos hemos referido y en la mayor parte los ordenamientos jurídicos internos, presenta ciertas dificultades en su concreción, sobre todo en relación con a las posibles limitaciones o restricciones del mismo respecto, por un lado, de los sujetos no nacionales de un Estado -sea que se encuentren en él de forma regular o irregular- $y$, por otro, en relación con las personas jurídicas.

En relación con primer aspecto -como sostiene DEL REAL-, desde la teoría general de los derechos fundamentales y desde la óptica del Estado de Derecho que la acompaña, no existe ninguna razón de peso que sustente suficientemente la restricción del acceso a la jurisdicción a los no nacionales; de darse, esta situación constituye un supuesto de indefensión. ${ }^{9}$

La Corte IDH ha sido enfática en señalar que el debido proceso legal es un derecho que debe ser reconocido en el marco de las garantías mínimas que se deben brindar a toda persona, independientemente de su estatus migratorio. "El amplio alcance de la intangibilidad del debido proceso se aplica no solo ratione materiae sino también ratione personae sin discriminación alguna"..$^{10}$ Esto implica que el Estado debe garantizar que toda persona extranjera, aún cuando fuere un migrante en situación irregular, tenga la posibilidad de hacer valer sus derechos y defender sus intereses en forma efectiva y en condiciones de igualdad procesal con otros justiciables. ${ }^{11}$

9 Del Real (2020), p. 28

10 Corte IDH. Opinión Consultiva OC-18/03, Condición jurídica y derechos de los migrantes indocumentados, párr. 121 y 122, 17/9/2003.

11 Corte IDH. Vélez Loor vs. Panamá, párr. 143, 23/11/2010. 
En lo que se refiere a la titularidad respecto de las personas jurídicas, la cuestión varía notablemente del sistema convencional europeo al interamericano y este difiere incluso de la mayoría de los sistemas nacionales que lo integran.

El art. 6.1 del CEDH reconoce a "toda persona" el derecho "a que su causa sea oída equitativa, públicamente y dentro de un plazo razonable por un tribunal" no distinguiendo, en consecuencia, si se trata de persona física o jurídica. Además, el art. 34 dispone que

"el Tribunal podrá conocer de una demanda presentada por cualquier persona física, organización no gubernamental o grupo de particulares que se considere víctima de una violación por una de las Altas Partes Contratantes de los derechos reconocidos en el Convenio o sus Protocolos. Las Altas Partes Contratantes se comprometen a no poner traba alguna al ejercicio eficaz de este derecho".

Conforme la jurisprudencia del TEDH, el concepto de organización no gubernamental se aplica a varios tipos de personas jurídicas privadas, sean de naturaleza civil o comercial, tengan o no fines de lucro, ${ }^{12} \mathrm{o}$ incluso a personas de derecho público siempre y cuando no ejerciten poderes gubernamentales, no hayan sido creadas para propósitos de administración pública y sean independiente del Estado. ${ }^{13}$

En el ámbito interamericano la solución es muy diferente. Si bien en la mayoría de los países de la región se reconocen directamente derechos fundamentales a las personas jurídicas, que pueden coincidir con aquellos consagrados en la Convención, se les otorga la posibilidad de interponer una acción de amparo o recursos análogos en defensa de los derechos que les son reconocidos; ${ }^{14}$ la Corte IDH ha entendido, desde

12 Entre otras: TEDH. SCI Boumois c. Francia, 17/6/2003; SCP Huglo, Lepage y Asociados, Consejo c. Francia, 1/2/2005; Klithropiia Ipirou Evva Hellas A.E. c. Grecia, 13 /1/ 2011; Sociedade Agricola Do Ameixial c. Portugal, 11 /1 2011; Tüketici Bilincini Geliştirme Derneği c. Turquia, 27/2/ 2007; Association Avenir d'Alet c. Francia, 14/2/ 2008.

13 TEDH. Islamic Republic of Iran Shipping Lines c. Turquía, párr. 80, 13/12/2007; Holy Monasteries c. Grecia, párr. 49, 9 /12/ 1994.

14 Corte IDH. Opinión Consultiva OC-22/16 Titularidad de derechos de las personas jurídicas en el Sistema Interamericano de Derechos Humanos, párr. 64 y 65, 26/2/2016. 
la primera oportunidad que tuvo de pronunciarse al respecto, que, a los efectos del art. 1.2 de la Convención, los derechos reconocidos en dicho instrumento corresponden a los seres humanos. ${ }^{15}$

En la Opinión Consultiva OC-22/16, en un examen detallado de la cuestión, la Corte resalta la diferencia con el sistema europeo -a pesar de constatar la similitud de la redacción del art. 44 de la Convención Americana y el 34 del CEDH-, en el sentido de que el último añade un requisito al establecer que puede presentar una petición cualquier persona "que se considere víctima de una violación por una de las Altas Partes Contratantes de los derechos reconocidos en el Convenio o sus Protocolos", lo que constituye una diferencia sustancial con el sistema interamericano, en el que se ha diferenciado entre peticionario y presunta víctima, de manera que el artículo 44 de la $\mathrm{CADH}$ hace referencia exclusivamente a la legitimación activa, en el sentido que establece que se pueden presentar peticiones individuales tanto a nombre propio como en el de terceras personas, sin que necesariamente deban confluir en la misma persona las dos categorías. ${ }^{16}$

Después de un análisis exhaustivo del tema, termina reiterándose en que

"de una interpretación del artículo 1.2 de la Convención Americana, de buena fe, acorde con el sentido natural de los términos empleados en la Convención (...) y teniendo en cuenta el contexto (...) y el objeto y fin de la misma (...), se desprende con claridad que las personas jurídicas no son titulares de derechos convencionales, por lo que no pueden ser consideradas como presuntas víctimas en el marco de los procesos contenciosos ante el sistema interamericano. ${ }^{17}$

De esta concepción individualista de la protección judicial de los dere-

15 Corte IDH. Cantos vs. Argentina, párr. 29, 7/12/2001; Perozo y otros vs. Venezuela, párr. 398, 28/1/2009; Usón Ramírez vs. Venezuela, párr. 45, 20/11/2009; Granier y otros (Radio Caracas Televisión) vs. Venezuela, párr. 19, 22/6/2015

16 Corte IDH. Opinión Consultiva OC-22/16, Titularidad de derechos de las personas jurídicas en el Sistema Interamericano de Derechos Humanos, párr. 55 y 56, 26/2/2016.

17 Corte IDH. Opinión Consultiva OC-22/16 Titularidad de derechos de las personas jurídicas en el Sistema Interamericano de Derechos Humanos, párr. 55 y 56, 26/2/2016. 
chos la Corte hace dos excepciones: respecto de los pueblos indígenas y comunidades tribales y en relación con los sindicatos.

En 2012, en el caso Pueblo Indígena Kichwa de Sarayaku Vs. Ecuador, la Corte IDH se aparta de su anterior jurisprudencia sobre el carácter individual de la titularidad de los derechos reconocidos en la Convención y reconoce por primera vez, como titulares de derechos por ella protegidos no solo a los miembros de una comunidad indígena sino a ésta en sí misma. ${ }^{18}$ En la OC-22/16, tomando en cuenta la cualidad de sujetos de derecho internacional de estos pueblos y comunidades, se reitera en su reciente jurisprudencia según la cual "las comunidades indígenas son titulares de derechos protegidos por el sistema interamericano y pueden presentarse ante este en defensa de sus derechos y los de sus miembros." 19

En relación con los sindicatos, la Corte IDH alude a los derechos reconocidos en el art. 8.1 del Protocolo de San Salvador de 17 de noviembre de $1988^{20}$ y que, a pesar de su redacción ambigua, en tanto no queda claro si confiere o no titularidad de derechos a los sindicatos, las federaciones y las confederaciones, considera que la interpretación más favorable de dicho precepto conlleva entender que allí se consagran derechos a favor de los sindicatos, las federaciones y las confederaciones, dado que son interlocutores de sus asociados y buscan salvaguardar y velar por sus derechos e intereses. Llegar a una conclusión diferente implicaría excluir el efecto de la Carta de la OEA y, por ende, desfavorecer el goce efectivo de los derechos en ella reconocidos. ${ }^{21}$ Debido a ello, concluye la

18 Corte IDH. Pueblo Indígena Kichwa de Sarayaku vs. Ecuador, puntos declarativos 2 a 4, 27 /6/2012.

19 Corte IDH. Opinión Consultiva OC-22/16 Titularidad de derechos de las personas jurídicas en el Sistema Interamericano de Derechos Humanos, párr. 72, 26/2/2016.

20 Protocola Adicional Sobre Derechos Humanos. Art. 8.- Derechos sindicales 1. Los Estados Partes garantizarán: a. El derecho de los trabajadores a organizar sindicatos y a afiliarse al de su elección, para la protección y promoción de sus intereses. Como proyección de este derecho, los Estados Partes permitirán a los sindicatos formar federaciones y confederaciones nacionales y asociarse a las ya existentes, así como formar organizaciones sindicales internacionales y asociarse a la de su elección. Los Estados Partes también permitirán que los sindicatos, federaciones y confederaciones funcionen libremente.

21 Corte IDH. Opinión Consultiva OC-22/16 Titularidad de derechos de las personas jurídicas en 
titularidad de los derechos establecidos en el artículo 8.1.a del Protocolo de los sindicatos, las federaciones y las confederaciones, lo cual les permite presentarse ante el sistema interamericano en defensa de sus propios derechos 22 .

Como conclusión de su análisis, la Corte matiza que, si bien la figura de las personas jurídicas no ha sido reconocida expresamente por la $\mathrm{CADH}$, esto no restringe la posibilidad de que bajo determinados supuestos el individuo que ejerza sus derechos a través de ellas pueda acudir al sistema interamericano para hacer valer sus derechos fundamentales, aun cuando los mismos estén cubiertos por una figura o ficción jurídica creada por el mismo sistema jurídico. ${ }^{23}$

\section{Estructura y contenido}

Antes habíamos señalado que el derecho a la tutela judicial efectiva se integra por otros derechos o garantías concretas que para el justiciable que se despliegan en tres momentos distintos: al acceder a la jurisdicción, durante el proceso y durante la ejecución de la sentencia. En esa línea, pudiéramos delimitar como estructura del derecho a la tutela judicial esos tres niveles de garantías: (i) las relativas al acceso a la justicia: tanto estructurales como procesales (epígrafe 3.1); (ii) las relativas al desarrollo del proceso (epígrafes 3.2 al 3.6) y las referidas a la efectividad de la decisión judicial (epígrafes 3.7 y 3.8), las que desarrollamos seguidamente.

\subsection{Derecho de acceso a la jurisdicción}

El libre acceso a los tribunales para solicitar de éstos la tutela de una situación subjetiva ha sido considerado como el contenido primordial y básico del derecho a la tutela judicial efectiva. ${ }^{24}$ En las Constituciones que lo han consagrado, ha sido empleado como baluarte para una pleni-

el Sistema Interamericano de Derechos Humanos, párr. 97, 26/2/2016

22 Corte IDH. Opinión Consultiva OC-22/16 Titularidad de derechos de las personas jurídicas en el Sistema Interamericano de Derechos Humanos, párr. 105, 26/2/2016

23 Corte IDH. Opinión Consultiva OC-22/16 Titularidad de derechos de las personas jurídicas en el Sistema Interamericano de Derechos Humanos, párr. 105, 26/2/2016

24 Diez Picazo (2000). 
tud en la protección de las situaciones jurídicas individuales, significando ello la preconización de la inexistencia de sectores del ordenamiento de los que deriven derechos subjetivos o intereses legítimos cuya vulneración no pueda ser impetrada ante los tribunales.

La efectividad del derecho de acceso a la jurisdicción exige que la persona "goce de la posibilidad clara y concreta de impugnar un acto que constituya una injerencia en sus derechos"25; es decir, no basta con que exista el reconocimiento formal del derecho a acudir a los jueces para deducir pretensiones, sino que exige la posibilidad real de que esta pueda ser examinada en cuanto al fondo. Por tanto, a pesar de la garantía formal de su existencia, este derecho pudiera verse afectado, según las circunstancias de cada caso por:

- el excesivo coste del proceso en relación con la capacidad económica del demandante: consignación de pagos previos excesivos (caución, solve et repet ${ }^{26}$ en materia tributaria o administrativa sancionadora, costas procesales muy elevadas);

- por la imposición de determinados plazos que hagan prácticamente imposible la interposición de la demanda o la subsanación de algún defecto procesal;

- por la existencia de obstáculos procesales que dificulten o impidan plantear la controversia ante el tribunal, especialmente por la interpretación excesivamente rigurosa y formalista de las normas procesales; ${ }^{27}$

- la existencia de normas procesales que impidan a determinada clase de sujetos ejercer el derecho de acceder a la jurisdicción.

25 TEDH. Bellet c. Francia, párr. 36, 4/12/1995,

26 Este principio ha sido declarado contrario al derecho de acceso a la justicia, p.ej., por el Tribunal Constitucional de Chile (TCC): Entre otras, las sentencias: Rol No. 1345-09-INC de 25/5/2009; Rol No. 1865-10-INA de 14/7/2011; Rol No. 1876-10-INA.de 9/8/2011.

27 TEDH. Pérez de Rada Cavanilles c. España, párr. 49, 28/10/1998; Miragall Escolano y otros c. España, párr. 38, 25/4/2000Api (f); Sotiris et Nikos Koutras ATTEE c. Grecia párr. 20, 16/2/2001 (f); Beles y otros c. República Checa, párr. 50, 12/2/2003 (f); RTBF c. Bélgica, párr. 71, 72, 74, $15 / 9 / 2011$ (f). 
El acceso a la jurisdicción, como la mayoría de los derechos, no tiene un carácter absoluto. Puede dar lugar a limitaciones admitidas implícitamente, pues por su propia naturaleza llama a una regulación por parte del Estado; "regulación que puede variar en el tiempo y el espacio en función de las necesidades y recursos de la comunidad y de los individuos, pero estas no pueden restringirlo de una manera o hasta un punto tales que el derecho se vea lesionado en su sustancia misma". ${ }^{28}$ Estas limitaciones sólo serían compatibles con el derecho fundamental si persiguen un objetivo legítimo, que responda a un fin de interés general y estén justificadas en la protección de otros derechos o principios constitucionales, que las condiciones y el alcance de la restricción estén determinados con suficiente precisión en la ley y exista una relación razonable de proporcionalidad entre los medios utilizados y el objetivo perseguido con la restricción. ${ }^{29}$

\subsection{Derecho a un tribunal independiente e imparcial}

La garantía de tutela judicial efectiva no se satisface únicamente con la existencia de jueces ante los que dirigir la pretensión, sino que exige además que estos sean independientes e imparciales. La independencia judicial es la principal garantía de la libertad en un Estado democrático. Ya el propio Montesquieu en su Espíritu de las Leyes lo sentenciaba:

"No hay libertad si el poder judicial no está separado del legislativo y el ejecutivo. Si está unido al legislativo, el poder de decidir de la vida y la libertad de los ciudadanos será arbitrario, porque el juez será al mismo tiempo legislador: si está unido al poder ejecutivo, el juez tendrá en su mano la fuerza de un opresor". 30

Ambos conceptos, independencia e imparcialidad, aunque tienen un

28 TEDH Philis c. Grecia ( $n^{\circ} 1$ ), párr. 59, 27/8/1991; De Geouffre de la Pradelle c. Francia, párr. 28, 16/12/1992; Stanev c. Bulgaria, párr. 229- 230, 17/1/2012; Ashingdane c. Reino Unido, párr. 57 28/5/1985; Fayed c. Reino Unido, párr. 65, 21/9/1994; Markovic y otros c. Italia, párr. 99, 14/12/2006.

29 TCE Sentencia No. 11/1981, de 8/4/1981.

30 Montesquieu (1906) pp. 228-229) También Hamilton (1787), p. 292 sostuvo que «no hay libertad, si el poder de la justicia no está separado de los poderes legislativo y ejecutivo». 
contenido y significado propios, tienen una estrecha relación de interdependencia, en tanto la primera es condición necesaria de la segunda. Un juez puede ser independiente sin ser imparcial (sobre una base caso por caso), pero un juez que no es independiente no puede, por definición, ser imparcial (sobre una base institucional). Las garantías de independencia e imparcialidad requieren reglas, particularmente en lo que respecta a la composición del órgano judicial y el nombramiento, la duración del servicio y los motivos de abstención, rechazo y despido de sus miembros, a fin de descartar cualquier duda razonable en la mente de las personas en cuanto a la impermeabilidad de ese organismo a los factores externos y su neutralidad con respecto a los intereses que tiene ante sí $^{31}$.

Independencia implica el ejercicio autónomo de las funciones del juez, sin ningún tipo de influencias de factores externos al Derecho y debe ser garantizada por el ordenamiento jurídico tanto en su vertiente institucional, esto decir, en relación con la estructura del sistema judicial, como también en conexión con su vertiente individual, o sea, en relación con la persona del juez. "El objetivo [es] evitar que el sistema judicial en general y sus integrantes en particular, se vean sometidos a posibles restricciones indebidas en el ejercicio de su función por parte de órganos ajenos al Poder Judicial o incluso por parte de quienes ejercen funciones de revisión o apelación». ${ }^{32}$

La vertiente institucional o estructural de la independencia impone la separación funcional y orgánica de los tribunales de cualquier otra estructura del poder del Estado. Aspecto de máxima relevancia de esta vertiente institucional de la independencia lo es la estabilidad de los jueces en el cargo. La Corte IDH ha establecido algunos parámetros que se han de considerar como garantías inherentes a la inamovilidad de los jueces ${ }^{33}$ :

31 Tribunal de Justicia de la Unión Europea (TJUE) Graham J. Wilson c. Ordre des avocats du barreau de Luxembourg, párr. 53, 19/9/2006,

32 Corte IDH. Rico vs. Argentina, párr. 53, 2/09/2019; San Miguel Sosa y otras vs. Venezuela, párr. 207, 8/02/2018; Apitz Barbera y otros ("Corte Primera de lo Contencioso Administrativo") vs. Venezuela, párr. 55, 5/08/2008.

33 Corte IDH Rico vs. Argentina, párr. 55, 2/09/2019; Valencia Hinojosa y otra vs. Ecuador, párr. $105,29 / 11 / 2016$. 
- que la separación del cargo obedezca exclusivamente a las causales permitidas, ya sea por medio de un proceso que cumpla con las garantías judiciales o porque se ha cumplido el término o período de su mandato;

- que los jueces y juezas solo pueden ser destituidos por faltas de disciplina graves o incompetencia;

- que todo proceso seguido en contra de jueces o juezas se resuelva de acuerdo con las normas de comportamiento judicial establecidas y mediante procedimientos justos que aseguren la objetividad e imparcialidad según la Constitución o la ley, puesto que la libre remoción de las autoridades judiciales fomenta la duda objetiva sobre la posibilidad efectiva de aquellos de decidir controversias concretas sin temor a represalias.

La independencia individual, por su parte, exige que los jueces estén libres no solo de influencias indebidas fuera del sistema judicial, sino también desde dentro; que no estén sujetos a órdenes o presiones de los demás jueces o de quienes tienen responsabilidades administrativas en el Tribunal (como el presidente de este o de alguna sala o sección).

La independencia judicial en el Estado democrático - apunta FERRAJOLI- se justifica en la garantía de dos valores esenciales que han de permanecer sustraídos de los consensos mayoritarios: los derechos fundamentales que no pueden sacrificarse a ninguna voluntad de y la sujeción de los poderes públicos al Derecho, que es la garantía máxima contra el arbitrio y contra las violaciones de la misma voluntad de la mayoría que produjo la ley. ${ }^{34}$

La jurisdicción en el Estado de Derecho -señala- se identifica y se legitima en la motivación fundada argumentos cognitivos en los hechos y recognitivos en el derecho, lo cual es suficiente para fundamentar su independencia frente a cualquier poder representativo de la mayoría (...) En la democracia constitucional la figura del juez, respecto de otros de los poderes del Estado se erige como un "contrapoder" en el doble sentido de

34 FerRajoli (2005), p. 96. 
que es el encargado del control de la legalidad sobre actos inválidos o ilícitos y, por consiguiente, sobre los daños que producen a los derechos de los ciudadanos. Para ejercer desempeñar ese papel desde luego no debe tener ninguna relación de dependencia, ni directa ni indirecta, ni externa ni interna, con ningún otro poder que pueda obstaculizarlo. ${ }^{35}$

En casos concretos, ha concluido el TEDH que "la ausencia de garantías suficientes para asegurar la independencia de los jueces dentro del poder judicial y, en particular, con respecto a sus superiores jerárquicos, puede llevar a concluir que las dudas del demandante sobre la independencia y la imparcialidad del tribunal pueden estar objetivamente justificadas", ${ }^{36}$ lo que resultaría en vulneración del derecho a un tribunal.

La imparcialidad, por su parte, requiere en el juez que resuelva el conflicto la ausencia subjetiva de todo sesgo o prejuicio y asimismo, el ofrecimiento de garantías que permitan descartar cualquier duda que el justiciable o la sociedad puedan albergar respecto de la ausencia de imparcialidad. La garantía de imparcialidad implica que quienes integran el tribunal no tengan un interés directo, una posición tomada, una preferencia por alguna de las partes y que no se encuentren involucrados en la controversia, y que inspiren la confianza necesaria a las partes en el caso, así como a los ciudadanos en una sociedad democrática. ${ }^{37}$

En la determinación de si existe o no imparcialidad - señala el TEDH en una amplia jurisprudencia- se deben tener en cuenta la convicción personal y el comportamiento de un juez en particular, es decir, si el juez sostuvo cualquier prejuicio personal o parcialidad en un caso determinado (enfoque subjetivo), así como si el tribunal proporcionó garantías suficientes (p. ej. en su composición) para excluir cualquier duda legítima a este respecto (enfoque objetivo); esto implica que al decidir si en un caso determinado hay una razón legítima para temer que un juez en particular carezca de imparcialidad, ese temor debe justificarse objetivamente, no

35 FERRAJOLI (2005), pp. 99- 100.

36 TEDH. Parlov-Tkalcic c. Croacia, párr. 86, 22/12/2009; Agrokompleks c. Ucrania, párr. 136, $8 / 3 / 2012$

37 TEDH. Wettstein c. Suiza, párr. 43- 45, 21/3/2001 (f); Micallef c. Malta, párr. 93, 15/10/2009, y Corte IDH. Rico vs. Argentina, párr. 70, 2/09/2019. 
sólo desde la perspectiva personal del interesado. ${ }^{38}$

Respecto del criterio de imparcialidad subjetiva, en principio debe aceptarse la presunción de que el juez es imparcial hasta que no se demuestre lo contrario. ${ }^{39}$ En lo que respecta al tipo de prueba requerida, por ejemplo, puede tratar de determinarse si un juez ha mostrado hostilidad o mala voluntad por razones personales. ${ }^{40}$ Entre imparcialidad subjetiva y objetiva, no existe una división hermética ya que la conducta de un juez no solo puede generar dudas objetivas sobre la imparcialidad desde el punto de vista del observador externo, sino que también puede referirse a sus problemas o sus convicciones personales. Por lo tanto, en algunos casos donde puede ser difícil obtener evidencia para refutar la presunción de imparcialidad subjetiva del juez, el requisito de imparcialidad objetiva proporciona otra garantía importante..$^{41}$

El examen objetivo significa determinar si, aparte de la conducta personal de alguno de los miembros del tribunal, existen hechos verificables que pueden plantear dudas en cuanto a su imparcialidad. De ello se deduce que cuando se decide si en un caso determinado existe una razón legítima para temer que un juez en particular o el tribunal carece de imparcialidad, el punto de vista de quienes lo afirman es importante pero no decisivo. Lo que es decisivo es si se puede considerar que el temor se justifica objetivamente..$^{42}$ La prueba objetiva se refiere principalmente a los vínculos jerárquicos o de otro tipo entre el juez y otros actores en el proceso. Por lo tanto, debe decidirse en cada caso individual si la relación en cuestión es de tal naturaleza y grado que indique una falta de

38 TEDH. Wettstein c. Suiza, párr. 43- 45, 21/3/2001 (f); Micallefc. Malta, párr. 93-101,15/10/2009. 39 Corte IDH. Rico vs. Argentina, párr. 70, 2/09/2019; TEDH. Otegui Mondragón y otros c. España, párr. 52-57, 6/11/2018.

40 TEDH. Micallef c. Malta, párr. 94,15/10/2009. El tribunal ha entendido, p.ej., que el hecho de que el presidente de un tribunal usara públicamente expresiones que implicaban que ya había tenido una opinión desfavorable del caso del demandante antes de presidir el tribunal que tenía que decidirlo, claramente parece incompatible con la imparcialidad requerida y se justifican objetivamente los temores del demandante en cuanto a esta. TEDH. Buscemi c. Italia, párr. 68, 16/9/1999.

41 TEDH. Micallef c. Malta, párr. 95, 15/10/2009; Korzeniak c. Polonia, párr. 49, 10/1/2017; Otegui Mondragón y otros c. España, párr. 31, 6/11/2018.

42 TEDH. Morel c. Francia, párr. 42, 18/10/2000 (f), 
imparcialidad por parte del tribunal. ${ }^{43}$

A este respecto, incluso las apariencias tienen cierta importancia o, en otras palabras, "la justicia no solo debe hacerse, sino que también debe parecer que se hace". Lo que está en juego es la confianza que los tribunales en una sociedad democrática deben inspirar en el público. En consecuencia, cualquier juez respecto de quien exista una razón legítima para temer una falta de imparcialidad debe apartarse del proceso. ${ }^{44}$

El derecho procesal intenta asegurar la apariencia de imparcialidad a través de las instituciones de la excusa y la recusación. La excusa constituye una expresión del compromiso ético del juez, que se retira voluntariamente del proceso ante la existencia de factores objetivos que pudieran afectar la apariencia de imparcialidad. La institución de la recusación, en consideración de la Corte IDH, tiene un doble fin: por un lado, actúa como una garantía para las partes en el proceso, y por el otro, busca otorgar credibilidad a la función que desarrolla la Jurisdicción. La recusación no debe ser vista necesariamente como un enjuiciamiento de la rectitud moral del funcionario recusado, sino más bien como una herramienta que brinda confianza a quienes acuden al Estado solicitando la intervención de órganos que deben ser y aparentar ser imparciales [...] En tal sentido, la recusación es un instrumento procesal destinado a proteger el derecho a ser juzgado por un órgano imparcial y no un elemento constitutivo o definitorio de dicho derecho. ${ }^{45}$

La existencia de reglas que regulen la retirada de los jueces de un asunto es un factor relevante, en tanto manifiestan la preocupación de las leyes por eliminar todas las dudas razonables que pudieran existir sobre la imparcialidad del juez o tribunal en cuestión. Además de garantizar la ausencia de sesgo real, están dirigidas a suprimir cualquier apariencia

43 TEDH. Micallef c. Malta, párr. 97,15/10/2009. El Tribunal cita, como ejemplos, los casos de la doble función del juez (Mežnarić c. Croacia, 15/7/2005), en el que un abogado representante de la contraparte de los demandantes luego juzga a esos propios demandantes en otros procesos relacionados.

44 TEDH. Micallef c. Malta, párr. 98, 15/10/2009.

45 Corte IDH. Apitz Barbera y otros (“Corte Primera de lo Contencioso Administrativo") vs. Venezuela, , párr. 63- 64, 5/8/2008. 
de parcialidad y, por lo tanto, sirven para promover la confianza que el sistema de justicia debe inspirar en la ciudadanía. ${ }^{46}$

Varias pueden ser las situaciones que pueden dar lugar a una fundada falta de imparcialidad del juez, tanto las de índole funcional como personal. Entre las primeras estarían: el ejercicio, dentro de un mismo proceso, de funciones simultáneas a la actividad jurisdiccional, sean consultivas o extrajudiciales; ${ }^{47}$ cuando en las distintas instancias de un mimo procedimiento se ejerce la doble función de parte y de juez;48 o en algunos casos de ejercicio de diferentes funciones judiciales en distintas etapas de un proceso. ${ }^{49}$ Entre las cuestiones de índole personal estaría el interés personal del juez en el asunto, ${ }^{50}$ o los vínculos profesionales o personales (directos o indirectos) que éste pueda tener con cualquiera de las partes. ${ }^{51}$

Por último, el alcance de la obligación del Estado de garantizar un juicio por un tribunal independiente e imparcial no se limita al poder judicial. También implica el deber para el ejecutivo, el legislativo y cualquier otra autoridad estatal, independientemente de su nivel, de respetar y acatar las sentencias y decisiones de los tribunales, incluso cuando no estén de acuerdo con ellas. Por lo tanto, el respeto por el Estado de la autoridad de los tribunales es una condición indispensable para la confianza de la ciudadanía en la justicia y, más ampliamente, del Estado de Derecho. Para ello, no son suficientes los postulados constitucionales de independencia e imparcialidad del poder judicial, sino que estos deben ser incorporados efectivamente en las actitudes y prácticas administrativas cotidianas. ${ }^{52}$

46 TEDH Micallef c. Malta, párr. 99, 15/10/2009.

47 TEDH Kleyn y otros c. Países Bajos, párr. 200, 6/5/2003; Procola c. Luxemburgo, párr. 45, 28/9/1995; McGonnell c. Reino Unido, párr. 52 al 58, 8/2/2000.

48 TEDH Wettstein c. Suiza, párr. 43- 47, 21/3/2001 (f); Mežnarić c. Croacia, párr. 36, 15/7/2005; Švarc y Kavnik c. Eslovenia, párr. 44, 8/5/2007 (f).

49 En particular, es necesario considerar si el vínculo entre las cuestiones de fondo determinadas en las distintas etapas del procedimiento es tan cercano como para poner en duda la imparcialidad del juez que participa en la toma de decisiones en estas etapas. TEDH Toziczka c. Polonia, párr. 36, 24/7/2012 (f).

50 TEDH. Langborger c. Suecia, párr. 35, 22/6/1989.

51 TEDH. Pescador Valero c. España, párr.27, 24/9/2003 (f).

52 TEDH. Agrokompleks c. Ucrania, párr. 136, 8/3/2012. 


\subsection{Derecho al juez ordinario predeterminado por la ley}

Una de las condiciones fundamentales de un debido proceso es que las normas que lo regulan permitan al justiciable identificar, con antelación, al juez que debe conocer su causa; en otras palabras, que aseguren el acceso al juez ordinario predeterminado por la ley, en contraposición con la existencia de jueces ad hoc o de excepción.

El fundamento de este derecho al "juez ordinario" o "juez legal" radica en garantizar, a priori, la imparcialidad del órgano juzgador, en el entendido de que un juez habilitado por la ley con carácter general para conocer de cualquier clase de controversias y no en función de las circunstancias particulares de un caso concreto sería un juez, en principio, imparcial. Contrariamente, podría estar comprometida la imparcialidad si la participación en la causa depende de la designación discrecional de cualquier autoridad, que pueda realizarse en atención a razones ajenas a la justicia misma.

En el caso Lori Berenson Mejía vs. Perú, la Corte IDH declara que "el derecho a ser juzgado por tribunales de justicia ordinarios con arreglo a procedimientos legalmente previstos constituye un principio básico del debido proceso. El Estado no debe crear tribunales que no apliquen normas procesales debidamente establecidas para sustituir la jurisdicción que corresponda normalmente a los tribunales ordinarios". ${ }^{53}$

El derecho al juez ordinario es, por tanto, una garantía instrumental de la imparcialidad judicial, cuyo contenido deriva de las regulaciones relativas a la constitución, jurisdicción y competencia del órgano juzgador y estaría integrado por algunas exigencias básicas:

- que la disposición jurídica por la que se crea el órgano juzgador y se le atribuye la jurisdicción sean previas al hecho que da lugar al proceso; esto es, básicamente, la institución de los distintos órdenes jurisdiccionales y la determinación genérica de su ámbito de conocimiento de los conflictos;

53 Corte IDH. Lori Berenson Mejía vs. Perú, párr. 143, 23/6/2005. 
- que la ley, también de manera previa y con carácter general, establezca las reglas de determinación de la competencia (material y territorial) de los órganos pertenecientes a cada orden jurisdiccional;

- que el régimen orgánico y procesal no permita considerar al juez o tribunal como órgano de excepción;

- que la composición del órgano jurisdiccional se realice de conformidad con las reglas generales previstas legalmente para la designación de sus miembros, sin incluirse en ellas la posibilidad de atribuir potestades discrecionales a cualquier autoridad, que permitan alterar dicha composición o designación.

\subsection{Derecho a una resolución de fondo, fundada en derecho}

La exigencia de la tutela judicial efectiva impone de suyo, desde el inicio mismo del proceso, la capacidad y el deber del tribunal de examinar todas las cuestiones de hecho del asunto planteado en cuanto al fondo de la controversia, sin limitarse a las cuestiones puramente jurídicas. No obstante este deber general de resolución sobre el fondo de las pretensiones procesales no supone incompatibilidad alguna con dicha garantía las decisiones de inadmisión fundadas en las específicas causales establecidas en la ley; causales que, en tanto restricciones a un derecho fundamental deberán responder, como ya hemos apuntado, a fines constitucionalmente legítimos o a la salvaguarda de otros principios o valores constitucionalmente relevantes y deben ser proporcionales a estos fines. Sin embargo, si la resolución de inadmisión obedece a una interpretación irrazonable o a la apreciación desmesurada y excesivamente formalista de los requisitos legales de acceso a la sentencia de fondo, si deviene en vulneración a la garantía de la tutela.

La formulación del llamado principio pro actione o favorecimiento del derecho de acción, responde precisamente a la exigencia de remover los obstáculos injustificados al acceso a la decisión de fondo que deriva del derecho a la tutela judicial efectiva, imponiendo no solo en un mandato positivo de interpretación en el sentido más favorable al derecho de acceso y, en todo caso, de no seleccionar la norma menos favorable, sino 
también "la interdicción de aquellas decisiones de inadmisión que por su rigorismo, por su formalismo excesivo o por cualquier otra razón revelen una clara desproporción entre los fines que aquellas causas preservan y los intereses que sacrifican", ${ }^{54}$ así como la exclusión de terminación del proceso por defectos subsanables.

En correspondencia con lo anterior y producto de elaboraciones jurisprudenciales se han extraído algunas consecuencias de la vigencia del principio pro-actione ${ }^{55}$, como pueden ser:

a. la posibilidad de subsanación de los defectos procesales, incluso si no existe una regulación legal expresa, previo a declarar la inadmisión de la demanda o la terminación del proceso;

b. la improcedencia de declarar la inadmisión de la demanda si ese efecto no se prevé expresamente en la disposición invocada ni fundarse en el incumplimiento de requisitos que no estén establecidos legalmente;

c. la ponderación, a favor del recurrente, de la intervención causal de tercero que hubiere resultado obstaculizadora del ejercicio del derecho de acción;

d. la necesidad de efectuar siempre una tarea de integración normativa, si posible, y no optar por una lectura aislada de la norma;

e. la aplicación de las normas que prevén la subsanación de los actos procesales con la mayor efectividad, para reducir en lo posible el catálogo de defectos insubsanables;

f. evitar eludir el pronunciamiento de fondo si de los escritos de parte se deduce claramente la pretensión, aunque no se haya incluido de forma expresa y concreta en el petitum de la demanda;

g. la improcedencia de rechazar un recurso porque no se haga mención expresa de la disposición que se considera infringida cuando del contenido y términos del recurso se deduzca, sin ninguna duda,

54 SÁEz LARA (2018), p. 756.

55 REMÓN (2018), pp. 731- 732. 
un cuestionamiento o censura de la resolución recurrida achacada a una indebida aplicación de la norma que el recurso considera decisiva.

El derecho a obtener una resolución de fondo no se satisface únicamente con el pronunciamiento de la sentencia una vez superados los presupuestos de admisibilidad, sino que exige además que la decisión pronunciada sea congruente, plena, razonable y fundada en Derecho.

Congruencia significa identidad entre el objeto de la controversia y la decisión del juez. La resolución judicial debe resolver todos los puntos de la litis de conformidad con las pretensiones formuladas por las partes. Existirá incongruencia, por tanto, cuando la resolución judicial no se ajusta a los términos del debate procesal, de manera que no exista correspondencia entre las pretensiones de las partes y lo que se concede en el fallo, ya sea por exceso (otorgando más de lo pedido -ultra petita- o resolviendo cosa distinta -extra petita-), o por defecto (concediendo menos -infra petita- u omitiendo resolver todos los puntos de la litis -citra petita).

La incongruencia "puede entrañar una vulneración del principio de contradicción constitutiva de una efectiva denegación del derecho a la tutela judicial siempre y cuando la desviación sea de tal naturaleza que suponga una sustancial modificación de los términos en los que discurrió la controversia procesal" 56 . La incongruencia omisiva entraña en todo caso una denegación de la tutela, precisamente por no dar respuesta a los motivos por los cuales se requirió la intervención judicial. La incongruencia por exceso, sin embargo, se consideraría contraria a la tutela sólo en la medida que exista "una modificación sustancial del objeto procesal, con la consiguiente indefensión y sustracción a las partes del verdadero debate contradictorio (...) de forma que la decisión judicial se haya pronunciado sobre temas o materias no debatidas oportunamente en el proceso y respecto de las cuales, por consiguiente, las partes no tuvieron la oportunidad de ejercitar adecuadamente su derecho de defensa"57

56 Tribunal Constitucional español (TCE) Sentencia 178 de 3/11/2014, FJ 6.

57 TCE Sentencia 178 de 3/11/2014, FJ 6. 
La plenitud de la tutela judicial alude a la capacidad del tribunal para juzgar y resolver todos los asuntos sometidos a su consideración. Solo merece la consideración de "tribunal" -en palabras del TEDH- un órgano que goza de jurisdicción plena. ${ }^{58} \mathrm{El}$ ejercicio de la plenitud jurisdiccional significa que el tribunal no renuncia a ninguno de los componentes que integran la función de juzgar, ${ }^{59}$ esto es, que tenga facultades para tratar todas las cuestiones de hecho y de derecho relacionadas con la controversia. ${ }^{60}$ Por tanto, las facultades de revisión limitada de los tribunales no constituyen una revisión judicial efectiva. ${ }^{61}$ Es condición entonces de la tutela efectiva que la sentencia examine, punto por punto los motivos de fondo del demandante, tanto los deseados como los reales, ${ }^{62}$ sin que pueda rehusarse a responder a ninguno de ellos o a investigar los hechos relevantes que formen parte de la cuestión principal de la demanda. ${ }^{63}$

En esa misma línea, la Corte IDH supedita la efectividad del recurso judicial a la suficiencia de los poderes de revisión del juez. Coincide con su homóloga europea en entender que existe una revisión judicial suficiente cuando el órgano judicial examina todos los alegatos y argumentos sometidos a su conocimiento sobre la decisión del órgano administrativo, sin declinar su competencia al resolverlos o al determinar los hechos. Por el contrario, estima que no hay una revisión judicial si el tribunal está impedido de determinar el objeto principal de la controversia, como por ejemplo sucede en casos en que se considera limitado por las determinaciones fácticas o jurídicas realizadas por el órgano administrativo que hubieran sido decisivas en la resolución del caso. ${ }^{64}$

En algunos ámbitos especializados de la actividad administrativa en los que los tribunales no pueden sustituir el juicio valorativo de los hechos que hace la Administración, el control pleno requiere evaluar y poder anu-

58 TEDH. Beaumartin c. Francia, párr. 38, 24/11/1994.

59 TEDH. Chevrol c. Francia, párr. 63, 13/5/2003.

60 TEDH. Terra Woningen B.V. c. Países Bajos, párr. 52, 17/12/1996.

61 TEDH. Obermeier c. Austria, párr. 70, 28/11/1990.

62 TEDH. Bryan c. Reino Unido, párr. 45, 22/11/1995.

63 TEDH. Potocka y otros c. Polonia, párr. 57, 27/3/2003.

64 Corte IDH. Barbani Duarte y otros vs. Uruguay, párr. 202 y 204, 13/10/2011. 
lar la decisión derivada de alguna interpretación arbitraria o irracional de los hechos. ${ }^{65}$

En casos concretos, el TEDH ha considerado que existe una falta de jurisdicción plena violatoria del derecho a una resolución de fondo cuando: un tribunal no puede investigar si las autoridades administrativas han empleado su facultad discrecional de forma compatible con el objeto y la finalidad de la ley; no tiene la facultad de apreciar la proporcionalidad que se da entre la falta y la sanción, o si para resolver se obligaba a seguir obligatoriamente la opinión una autoridad administrativa determinante para el resultado de la controversia-, sin someter a crítica ni a un debate contradictorio dicha opinión. ${ }^{6}$

La razonabilidad de la decisión judicial se ha de juzgar en función de la motivación, esto es, de la exposición racional de todo el desarrollo argumental del juez, contentivo de todos los elementos de juicio que permitan conocer y controlar las razones jurídicas en las que ha basado su decisión.

El ideal del Estado constitucional (la culminación del Estado de derecho) -apunta ATIENZA- supone el sometimiento completo del poder al derecho, a la razón: la fuerza de la razón, frente a la razón de la fuerza, por lo que parece bastante lógico que el avance del Estado constitucional haya ido acompañado de un incremento cuantitativo y cualitativo de la exigencia de justificación de las decisiones de los órganos públicos. ${ }^{67}$

El deber de motivar las resoluciones judiciales es una garantía vinculada con la correcta administración de justicia en tanto protege el derecho de los ciudadanos a ser juzgados por las razones que el Derecho suministra y otorga credibilidad de las decisiones jurídicas en el marco de una sociedad democrática. La argumentación debe permitir conocer los motivos en que se basó la autoridad para tomar su decisión, a fin de descartar cualquier indicio de arbitrariedad ${ }^{68}$.

65 TEDH. Bryan c. Reino Unido, párr. 44 al 47, 22/11/1995; Crompton c. Reino Unido, párr. 70 al $73,12 / 3 / 2002$,

66 TEDH- Consejo de Europa (2013), p. 24

67 ATIENZA (2005), p. 11.

68 Corte IDH. Maldonado Ordoñez vs. Guatemala, párr. 87, 3/5/2016; TEDH. Suominen c. Fin- 
La argumentación de los fallos debe mostrar que los alegatos de las partes han sido debidamente tomados en cuenta y que ha sido analizado el conjunto de pruebas. Asimismo, "la motivación demuestra a las partes que éstas han sido oídas y, en aquellos casos en que las decisiones son recurribles, les proporciona la posibilidad de criticar la resolución y lograr un nuevo examen de la cuestión ante las instancias superiores". ${ }^{69}$ "Solo mediante una decisión razonada puede haber un escrutinio público de la administración de justicia". ${ }^{70}$

La obligación de los tribunales de motivar sus decisiones no significa la exigencia de una respuesta detallada a cada argumento, ${ }^{71}$ pero cuando estos resulten decisivos para la solución del procedimiento, exigirán una respuesta específica y explícita. ${ }^{72}$ Cuando se trata de la solución de un recurso, si el tribunal ha motivado brevemente su decisión - incorporando los motivos suministrados por un órgano judicial inferior o de otra manera-, es necesario que acredite haber examinado realmente las cuestiones esenciales que se le han planteado y que no se contente con apoyar pura y simplemente las conclusiones de un órgano judicial inferior, tanto más cuando una parte no haya podido presentar oralmente su causa. ${ }^{73}$

La exigencia de motivación no se satisface, sin embargo, con cualquier tipo de argumentos, sino que debe ser una motivación razonable. De esta manera, la decisión judicial puede tenerse por no motivada a pesar de la existencia formal de argumentos,

cuando el razonamiento que la funda incurra en tal grado de arbitrariedad, irrazonabilidad o error que, por su evidencia y contenido, sean tan manifiestos y graves que para cualquier observador resulte patente que la resolución de hecho carece de toda motivación o razonamiento. [No lo

landia, párr. 34, 1/7/2003.

69 Corte IDH. Apitz Barbera y otros («Corte Primera de lo Contencioso Administrativo») vs. Venezuela, párr. 78, 5/8/2008; TEDH. Suominen c. Finlandia, párr. 37, 1/7/2003.

70 TEDH. Suominen c. Finlandia, párr. 37,1/7/2003; Hirvisaari c. Finlandia, párr. 30, 27/9/2001.

71 TEDH. Van de Hurk c. Países Bajos, párr. 61, 21/4/1994; García Ruiz c. España, párr. 26, 21/1/1999.

72 TEDH. Ruiz Torija c. España, párr. 30, 9/12/1994

73 TEDH. Helle c. Finlandia, párr. 60, 19/12/1997 
estarían, por tanto, aquellas resoluciones que] a primera vista y sin necesidad de mayor esfuerzo intelectual y argumental, se comprueba que parten de premisas inexistentes o patentemente erróneas o siguen un desarrollo argumental que incurre en quiebras lógicas de tal magnitud que las conclusiones alcanzadas no pueden considerarse basadas en ninguna de las razones aducidas. ${ }^{74}$

El requerimiento de la motivación implica además el carácter jurídico de esta, o sea, que la decisión no sea el producto de los criterios de justicia material del juez, sino que debe estar fundada en el sistema de fuentes establecido y según los métodos de interpretación proporcionados por el Derecho. Una resolución fundada en Derecho implica la argumentación razonable de la decisión en aplicación del ordenamiento jurídico vigente; es decir, que a través del razonamiento lógico en que consiste la motivación se pueda concluir la conexión directa entre la decisión adoptada y la norma jurídica que le sirve de cobertura.

La exigencia de la fundamentación en derecho de la resolución, en consecuencia, no se cumple únicamente con la garantía de la motivación ni con la mera invocación del ordenamiento jurídico. El contenido de la motivación debe fundarse en el sistema de fuentes reconocido y consistir en la justificación razonable de la elección e interpretación de la norma, de manera que no incurra en una aplicación arbitraria, o simplemente aparente, de la legalidad. En ese sentido, el derecho a la tutela judicial se vería quebrantado, cuando, con independencia de la entidad o calidad de la motivación el tribunal no acierta, de forma evidente, en la elección o la interpretación de la norma aplicable, de forma tal que la solución adoptada resulte manifiestamente injusta o ilegal y, por tanto, no fundada en Derecho.

\subsection{Derecho a un debido proceso con garantías}

El derecho a un proceso con garantías, o «debido proceso» ha de entenderse como la concurrencia de unos presupuestos y condiciones

74 TCE, Sentencia 214 de 24/11/1999, FJ 4. 
mínimas que deben respetarse desde el inicio y durante todo el transcurso de la actividad jurisdiccional a fin de asegurar la decisión justa de la controversia. La Corte IDH lo ha definido, a partir del artículo 8 de la Convención, como «el conjunto de requisitos que deben observarse en las instancias procesales a efectos de que las personas estén en condiciones de defender adecuadamente sus derechos ante cualquier tipo de acto del Estado que pueda afectarlos». ${ }^{75} \mathrm{El}$ derecho al debido proceso -en los términos de la Corte Constitucional ecuatoriana, es «el eje articulador de la validez procesal, ya que la vulneración de sus garantías constituye un atentado grave a los derechos de las personas dentro de una causa». ${ }^{76}$

Dentro de las garantías básicas que integran el debido proceso se pudieran sistematizar; (i) el derecho a la defensa, con sus garantías instrumentales; (ii) la equidad procesal o "igualdad de medios"; (iii) el derecho de contradicción y (iv) la publicidad del proceso.

\subsubsection{Derecho a la defensa}

El derecho fundamental de toda persona a ser oída públicamente y con justicia por un tribunal significa la posibilidad de que esta pueda exponer dentro del proceso, cuantos argumentos y materiales, fácticos y jurídicos, fueren necesarios para sostener su causa frente a las actuaciones procesales de la otra parte o del órgano jurisdiccional.

Definido así, el derecho a la defensa supone entonces la capacidad y posibilidad de intervención activa de los interesados en el proceso y comprende otras garantías instrumentales como:

- el derecho a ser informado; el cual, en la más extensa interpretación del Tribunal Constitucional alemán, comprende el conocimiento de las alegaciones de la parte contraria (incluyendo los anexos documentales); la información de aquellos hechos que, aunque fueren

75 Corte IDH. Rico vs. Argentina, párr. 49, 2/09/2019; Colindres Schonenberg vs. El Salvador, párr. 63, 4/02/2019; Tribunal Constitucional vs. Perú, párr. 69, 31/01/2001.

76 Corte Constitucional del Ecuador (CCE), Sentencia No. 208-17-SEP-CC/ 2017, p. 14 
manifiestos, pudieran ser desconocidos por una de las partes; los hechos y los medios de prueba admitidos por el tribunal; los hechos constatados que tengan su origen en otro proceso. Corresponde al tribunal hacerlo efectivo sin que sea necesaria instar la información; ${ }^{77}$

- el derecho de las partes a presentar las observaciones que consideren oportunas; este derecho sólo puede ser efectivo si estas observaciones son realmente "entendidas", es decir debidamente examinadas por el Tribunal al que se recurre. ${ }^{78}$ Los plazos que se dispongan para presentar las alegaciones habrán de ser objetivamente suficientes y proporcionales a la finalidad de la defensa;

- el derecho a proponer las pruebas y a que sean admitidas y practicadas si cumplen con los requisitos procesales establecidos sobre la idoneidad, necesidad, pertinencia y legitimidad de los medios que se proponen;

la posibilidad de impugnar las decisiones del órgano jurisdiccional mediante los recursos que determine la ley. En todo caso debe asegurarse el debate contradictorio, en tanto expresión del ejercicio simultáneo del derecho a la defensa de los sujetos procesales, así como el respeto al principio de igualdad de armas procesales.

Las modalidades de ejercicio del derecho a la defensa son dos: la autodefensa, que supone la comparecencia y ejercicio personal de las actuaciones procesales por el interesado, en la medida que así lo permita la ley; y la defensa técnica, que se realiza mediante la asistencia letrada.

A) Derecho a la defensa técnica o asistencia letrada. La asistencia letrada o defensa técnica se refiere al asesoramiento, defensa y representación por un profesional del Derecho -ante todo, de la propia elección de la parte- y que incluye, a su vez (i) la calidad de la asistencia, (ii) el derecho a disponer del tiempo y de los medios adecuados para la preparación de la propia defensa y (iii) el derecho a renunciar a la representación.

77 BARNÉs (1993), p. 205.

78 TEDH. Iglesias Casarrubios y Cantalapiedra Iglesias c. España, párr. 35, 11/10/2016. 
Se trata de un derecho subjetivo de carácter instrumental del derecho a la defensa, incluido dentro del grupo de garantías del debido proceso y cuya finalidad asegurar la efectiva realización de los principios de igualdad de partes y de contradicción, que imponen a los órganos judiciales el deber positivo de evitar desequilibrios entre la respectiva posición procesal de las partes o limitaciones en la defensa que puedan generar a alguna de ellas resultado de indefensión; ${ }^{79}$ por lo que en algunas ocasiones constituye exigencia estructural del proceso y garantía de su correcto desarrollo.

Ahora bien, respecto de la defensa técnica debe distinguirse entre la exigencia procesal de asistencia letrada y el derecho a designar y hacerse representar por abogado. El requisito procesal de asistencia letrada viene determinado precisamente por la finalidad misma del derecho a la defensa técnica, esto es, la de garantizar el equilibrio entre las partes y con ello la contradicción efectiva en el debate procesal; pero ello no debe tener un carácter absoluto, en el sentido de negar el derecho a la autodefensa. Así, se haría necesaria desde la perspectiva del derecho a la tutela judicial efectiva la exigencia procesal de asistencia letrada, sólo cuando la complejidad técnica de la materia controvertida o de los procedimientos a seguir conviertan la autodefensa en un medio inadecuado o inútil para garantizar la justicia.

La posibilidad de las partes de deducir ante el juez personalmente sus pretensiones por la ausencia de obligatoriedad del requisito de la postulación letrada en algunos procesos no hace decaer el derecho a la defensa técnica, pues en tales supuestos no se obliga a las partes a defenderse personalmente, sino que les concede el poder para escoger entre la autodefensa y la asistencia del abogado, quedando, por tanto, a salvo el mencionado derecho que puede renunciar o ejercer según estime conveniente.

El derecho a la defensa técnica en los proceso no penales no implica -a diferencia de los penales-, que el Estado deba proporcionar la asistencia jurídica gratuita. Tal obligación existiría cuando la asistencia

79 TCE. Sentencias 38/2003, 60/2003, 198/2003, 145/2002. 
jurídica resulte indispensable para poder acceder de forma efectiva a los órganos jurisdiccionales, ya sea porque es legalmente exigida la asistencia de letrado o cuando no siéndolo, la complejidad del proceso, la capacidad intelectual y la situación económica del solicitante comprometan la posibilidad de defender efectivamente su caso ${ }^{80}$, ante la imposibilidad de costear los servicios de un abogado de su elección. De lo que se trata -dice el TEDH-, es de saber si, habida cuenta del conjunto de circunstancias, la falta de asistencia jurídica privada sustrae a la parte de un juicio justo e infringe su derecho a presentar efectivamente su defensa. ${ }^{81}$

La jurisprudencia constitucional española ha sentado que la negación del derecho a la asistencia letrada gratuita en proceso que permite la comparecencia personal constituiría una vulneración del derecho a la tutela,

si la autodefensa ejercitada por aquél a quien se niega el derecho se manifiesta incapaz de compensar la ausencia de Abogado que lo defienda $y$, por lo tanto, de contribuir satisfactoriamente el examen de las cuestiones jurídicas suscitadas en el proceso, lo cual será determinable, en cada caso concreto, atendiendo a la mayor o menor complejidad del debate procesal y a la cultura y conocimientos jurídicos del comparecido personalmente, deducidos de la forma y nivel técnico con que haya realizado su defensa. ${ }^{82}$

Un aspecto importante que debe considerarse dentro de este apartado de la asistencia técnica gratuita como garantía de la tutela judicial efectiva tiene que ver con la calidad de la defensa. Si bien la conducta procesal del abogado es de su entera responsabilidad, la designación e intervención de un abogado en virtud de la asistencia jurídica debe responder imperativamente a normas de calidad; estas normas no se cumplen si los fallos del sistema de asistencia jurídica privan a los justiciables

80 TEDH. Airey c. Irlanda, párr. 26, 9/10/1979; Steel y Morris c. Reino Unido, párr. 61, 15/5/2005 (f); P., C. y S. C. Reino Unido, párr. 100, 16/10/2002 (f); McVicar c. Reino Unido, párr. 48- 62, $7 / 08 / 2002$ (f).

81 TEDH. McVicar c. Reino Unido, párr. 51, 7/08/2002.

82 TCE. Sentencia No. 47/1987, fj 3. 
del acceso "concreto y efectivo" a un tribunal al que tienen derecho. ${ }^{83} \mathrm{La}$ defensa suministrada por el Estado a quien no pudiera defenderse por sí mismo ni nombrar defensor particular debe ser efectiva, para lo cual debe adoptar las medidas tendentes a ese fin, ${ }^{84}$ fundamentalmente, debe velar por que haya un equilibrio entre el acceso a la justicia y la independencia de los abogados.

B) Derecho a recurrir el fallo. La disponibilidad de medios de impugnación contra las sentencias no penales, a diferencia de las previstas para las de materia penal, no constituye una garantía del derecho a la tutela judicial efectiva desde la perspectiva de las convenciones americana y europea $^{85}$ de Derechos Humanos, por lo que, en principio, este derecho quedaría garantizado con el acceso a la primera instancia. Consecuentemente, el derecho a recurrir la sentencia, contrariamente al derecho de acceso a la jurisdicción, no tiene un carácter universal y se integra al derecho a la tutela judicial efectiva en la medida en que así lo prevean los respectivos ordenamientos jurídicos nacionales.

En buena parte de los ordenamientos europeos, el derecho al recurso no forma parte del contenido constitucional de la tutela judicial efectiva, sino que depende de la configuración que reciba de cada una de las leyes de enjuiciamiento, como una cuestión de legalidad ordinaria, "correspondiendo al ámbito de libertad del legislador el establecimiento y regulación de los recursos procedentes en cada caso, siendo incluso posible que no existan" 86 .

En algunos ordenamientos latinoamericanos, donde el derecho al recurso sí encuentra amparo expreso en la Constitución, como en Ecua-

83 TEDH. Staroszczyk c. Polonia, párr. 135, 22/3/2007.

84 Corte IDH. Chaparro Álvarez y Lapo Íñiguez vs. Ecuador, párr. 159, 21/11/2007.

85 TEDH. Platakou c. Grecia, párr. 38, 5/9/2001 (f). «El Tribunal reitera que el artículo 6 del Convenio no obliga a los Estados contratantes a crear tribunales de apelación o casación. Sin embargo, un Estado que adopta una jurisdicción de esta naturaleza tiene la obligación de garantizar que las personas disfruten en ellas de las garantías fundamentales del Artículo 6».

86 TCE, sentencias: 105/2006, FJ 3; 149/2015, FJ 3; 176/2016, FJ 3. 
dor $^{87}$, Perú ${ }^{88}$ o Colombia, ${ }^{89}$ sea dentro del conjunto de garantías comunes a todos los procesos o entre los principios que presiden la función jurisdiccional, la jurisprudencia constitucional ha matizado su alcance. Así, la Corte Constitucional ecuatoriana ha determinado, sin mayor detalle, que

la posibilidad de recurrir de una decisión judicial no tiene el carácter de absoluto, en el sentido de que no en todo proceso y no toda decisión judicial es susceptible de ser impugnada, apelada o recurrida sin que esto traiga consigo una evidente vulneración del derecho al debido proceso en la garantía de recurrir la decisión judicial o el derecho a la doble instancia puesto que, la posibilidad de recurrir estará regulada por la norma legal pertinente, de acuerdo a la naturaleza y alcance de cada uno de los procesos jurisdiccionales que nuestro ordenamiento jurídico reconoce..$^{90}$

El Tribunal Constitucional peruano (TCP), con mayor precisión, fija como contenido esencial del derecho fundamental a la pluralidad de la instancia el derecho de toda persona a un recurso eficaz, en procesos no penales, contra la sentencia u otra resolución con vocación de poner fin al proceso "a menos que haya sido emitida por un órgano jurisdiccional colegiado y no limite el contenido esencial de algún derecho fundamental". ${ }^{91}$ Por su parte, la Corte Constitucional colombiana (CCC) ha declarado que la doble instancia no pertenece al núcleo esencial del debido proceso, -pues la ley puede consagrar excepciones, ${ }^{92}$

sin embargo - dice-, el hecho de que la doble instancia sólo haga parte del contenido esencial del debido proceso en las acciones de tutela y en materia penal, no significa que la ley pueda establecer excepciones

87 Art. 76, Constitución de la República del Ecuador: «En todo proceso en el que se determinen derechos y obligaciones de cualquier orden, se asegurará el derecho al debido proceso que incluirá las siguientes garantías básicas...7) El derecho de las personas a la defensa incluirá las siguientes garantías... m) recurrir el fallo o resolución en todos los procedimientos en los que se decida sobre sus derechos;

88 Art. 139, Constitución Política del Perú: «Son principios y derechos de la función jurisdiccional: 6 . La pluralidad de la instancia»

89 Art. 31 de la Constitución Política: «Toda sentencia judicial podrá ser apelada o consultada, salvo las excepciones que consagre la ley».

90 CCE. Sentencia, No. 208-17-SEP-CC/ 2017, p. 15.

91 TCP. Sentencia No. 4235-2010-PHC/TC, 11/8/2011, párr. 25.

92 CCC. Sentencia No. C-345/93 de 1993. 
a la doble instancia en cualquier tipo de proceso, por las siguientes tres razones: De un lado, el principio general establecido por el artículo 31 superior es que todos los procesos judiciales son de doble instancia. Por consiguiente, como los procesos de única instancia son una excepción a ese principio constitucional, es obvio que debe existir algún elemento que justifique esa limitación. Otra interpretación conduciría a convertir la regla (doble instancia) en excepción (única instancia). ${ }^{93}$

\subsubsection{Derecho a un proceso equitativo}

La equidad procesal se define por la existencia de un proceso contradictorio en el que las partes son escuchadas y consideradas en pie de igualdad ante el juez. El carácter equitativo del proceso ha de considerarse tomándolo en su conjunto, de manera que una irregularidad aislada no bastaría para que todo el procedimiento se tornase no equitativo. La noción de proceso equitativo comprende dos aspectos esenciales: (i) la igualdad de medios procesales o igualdad de armas y (ii) el derecho a la contradicción en la instancia.

La igualdad de los medios procesales se refiere al deber de ofrecer a cada parte una oportunidad razonable para presentar su caso, incluidas sus pruebas, en condiciones que no la coloque en una situación de clara desventaja en comparación con su oponente. ${ }^{94}$ Serían contrarios por tanto al principio de igualdad de medios procesales, p.ej.: permitir alegaciones a una de las partes (incluyendo la presentación de los recursos), sin darle a la otra oportunidad de réplica; realizar actos procesales que favorezcan a una de las partes en detrimento de la otra como la suspensión de plazos, no permitir acceso o informaciones o práctica de pruebas a una de las partes o permitir desequilibrios en cuando a los tiempos un oportunidades de intervención de las partes. ${ }^{95}$ También es contario al derecho de igualdad procesal el hecho de que, en el ámbito contencioso administrativo se admita que la Administración se limite a justificar sus

93 CCC. Sentencia No. C-934/06, de 2006.

94 TEDH. Dombo Beheer B.V. c. Países Bajos, párr. 33, 27/10/1993.

95 TEDH. Entre otras: Beer c. Austria, párr. 19, 6/2/2001; Platakou c. Grecia, párr. 48, 5/9/2001; Dombo Beheer B.V. c. Países Bajos, párr. 34 y 35, 27/10/1993. 
decisiones mediante formulaciones muy generales o resumidas que no permitan presentar una oposición razonada..$^{96}$

El derecho a un procedimiento contradictorio implica la facultad de cada parte de conocer las observaciones o pruebas presentadas por la otra, o tener conocimiento de cualquier documento u observación presentada al juez, incluso por un magistrado independiente, para influir en su decisión y poder discutirla.$^{97}$ Sólo corresponde a las partes evaluar si los documentos u opiniones presentadas le merecen algún comentario. La confianza de los justiciables en la justicia se basa, entre otras cosas, en la seguridad de poder expresarse sobre cualquier pieza que conforme el expediente, incluyendo las de oficio. ${ }^{98}$

\subsubsection{Publicidad del proceso}

La publicidad del proceso protege a los justiciables contra una justicia secreta que escapa al control del público. Es uno de los medios de preservar la confianza en los tribunales y constituye una importante garantía del debido proceso en tanto imprime transparencia a la administración de justicia. ${ }^{99}$

No obstante la exigencia de publicidad, excepcionalmente la celebración de las audiencias pueden celebrarse a puertas cerradas, por razones de moralidad, de orden público, de seguridad nacional, para la protección de los intereses de los menores o la intimidad de las partes, o en la medida en que sea considerado estrictamente necesario por el tribunal cuando en circunstancias especiales la publicidad pudiera ser perjudicial para los intereses de la justicia. Aparte de las circunstancias absolutamente excepcionales, los litigantes deben al menos tener la oportunidad de solicitar una audiencia pública e incluso objetar la decisión del tribunal. ${ }^{100}$

En determinados casos, sin embargo, puede prescindirse de la cele-

96 TEDH. Hentrich c. Francia, párr. 56, 22/9/1994.

97 TEDH. Ruiz-Mateos c. España, párr. 63, 23/6/1993; McMichael c. Reino Unido, párr. 80, 24/2/1995; Vermeulen c. Bélgica, párr. 33, 20/2/1996.

98 TEDH. Nideröst-Huber c. Suiza, párr. 29, 18/2/1997; K.S. c. Finlandia, párr. 22, 12/12/2001.

99 TEDH. Pretto y otros c. Italia, párr. 21, 8/12/1983.

100 TEDH. Martinie c. Francia, párr. 42, 12/4/2006. 
bración de audiencia. Ello sucede, por ej.: si una parte renuncia de manera inequívoca a su derecho a ello y no hay cuestiones de interés público que la hagan necesaria; cuando las cuestiones del debate se limiten a aspectos puramente jurídicos ${ }^{101} \mathrm{o}$ de índole altamente técnica, en los que no sean necesarios debates orales.

\subsection{Derecho a un proceso sin dilaciones indebidas}

Tanto el TEDH como la Corte IDH resaltan la importancia de que la justicia se realice en un tiempo razonable, sin dilaciones que puedan comprometer su eficacia y credibilidad. ${ }^{102} \mathrm{El}$ término de plazo razonable, abarca en principio a todas las fases del proceso, extendiéndose, en consecuencia, a las instancias que resuelven los recursos y la de ejecución de la sentencia. Sólo puede, por tanto, declararse concluido el proceso cuando el derecho declarado sea efectivamente realizado. ${ }^{103}$

La razonabilidad de la duración de un proceso debe evaluarse a la luz de las circunstancias de este en relación con: ${ }^{104}$

- la complejidad del asunto, en función de los hechos que se juzgan, el derecho aplicable, la pluralidad de partes intervinientes o los distintos elementos de prueba que deben obtenerse y practicarse;

- la conducta de las partes, en la medida en que actúen con la debida diligencia en los actos que les afecten, no recurran a maniobras dilatorias y exploten las posibilidades ofrecidas por el ordenamiento para abreviar el proceso;

101 TEDH Döry c. Suecia, párr. 37, 12/2/2003; Allan Jacobsson c. Suecia, párr. 48 y 49, 19/2/1998; Valovâ y otros c. Eslovaquia, párr. 65 al 68, 1/9/2004 (f); Schuler-Zgraggen c. Suiza, párr. 58, 24/6/1993.

102 TEDH. H. c. Francia, párr. 58, 24/10/1989; Katte Klitsche de la Grange c. Italia, párr. 61,19/9/1994: Corte IDH. Anzualdo Castro vs. Perú, párr. 156, 22/9/2009;

103 TEDH. Poiss c. Austria, párr. 50, 24/3/1987; Robins c. Reino Unido, párr. 28 y 29, 23/9/1997; Martins Moreira c. Portugal párr. 44; 23/3/1994, Silva Pontes c. Portugal, párr. 33, 7/10/1988; Di Pede c. Italia, párr. 24; 21/4/1998; Estima Jorge c. Portugal, párr. 36 al 38, 20/8/1996

104 TEDH. Frydlender c. Francia, párr. 43, 27/6/2000; Katte Klitsche de la Grange c. Italia, párr. 55, 19/9/1994; Humen c. Polonia, párr. 63, 15/10/1999; Unión Alimentaria Sanders S.A. c. España, párr. 35, 7/7/1989; Corte IDH. Anzualdo Castro vs. Perú, párr. 156, 22/9/2009; Valle Jaramillo y otros vs. Colombia, párr. 155, 27/11/2008; Kawas Fernández vs. Honduras, párr. 112, 3/4/2009; Montesino Mejía vs. Ecuador, párr. 179, 27/1/2020. 
- el comportamiento de las autoridades: por un lado, en la medida en que los jueces cumplan su responsabilidad de garantizar la celeridad de los procesos, adoptando las medidas necesarias a ese fin, aun a pesar de las maniobras dilatorias de las partes y, por otro, en la medida en que los aspectos relacionados con la organización y los administrativos garanticen la disponibilidad de recursos puestos a disposición de la justicia que eviten la excesiva acumulación de asuntos y la sobrecarga de trabajo o el cambio frecuente de jueces; ${ }^{105}$

- la postura o naturaleza del litigio; en el sentido de que existen procesos que por la naturaleza de las pretensiones que están en juego requieren de una celeridad particular. ${ }^{106}$

\subsection{Derecho a la ejecución}

La tutela judicial solo podría considerarse "efectiva" si el resultado final de la actividad jurisdiccional desplegada en el proceso conduce a la coronación práctica de los derechos o situaciones subjetivas reconocidas en la sentencia. No basta, entonces, con el respeto formal de los fallos judiciales, sino que se precisa su comprobación en el terreno de los hechos. La ejecución de las sentencias deviene entonces -en palabras de la jurisprudencia constitucional italiana, «contenido intrínseco y esencial de la misma función jurisdiccional» ${ }^{107}$ y por consecuencia, la garantía última de la efectividad de la justicia.

El derecho a la tutela judicial - dice el TEDH-

sería ilusorio si el ordenamiento jurídico permitiera que una decisión judicial definitiva y vinculante permaneciera inoperante en detrimento de una parte. De hecho, no se entendería que el artículo 6 párr. 1 [del CEDH] describe en detalle las garantías procesales (imparcialidad, publicidad y prontitud) otorgadas a las partes y que no protege la implementación de

105 TEDH. Scordino c. Italia ( $n^{\circ}$ 1), párr. 183, 29/3/2006; Vocaturo c. Italia párr. 17, 24/4/1991. 106 TEDH. Comingersoll S.A. c. Portugal, párr. 19, 6/4/2000; Frydlender c. Francia, párr. 43, 27/6/2000; Raspopović y otros c. Montenegro, párr. 7, 26/3/2020.

107 Corte Costituzionale italiana (CCI) Sentencia No. 419/1995 de 8/9/1995. 
las decisiones judiciales. Si el derecho a la tutela judicial se interpretara como referida exclusivamente al acceso al juez y al desarrollo de los procedimientos, crearía situaciones incompatibles con el principio del Estado de Derecho. La ejecución de una sentencia de cualquier jurisdicción debe, por lo tanto, considerarse como parte integral del proceso. ${ }^{108}$

La protección efectiva del litigante y el restablecimiento de la legalidad implican la obligación de la Administración de cumplir con la sentencia dictada. La Administración es un elemento del Estado de derecho y, por ende, su interés se identifica con el de una buena administración de justicia. Si la administración se niega a cumplir la sentencia o se demora en hacerlo, las garantías procesales no tendrían sentido. ${ }^{109}$

En la misma línea, la Corte IDH ha declarado que, que en los términos del artículo 25 de la $\mathrm{CADH}$, corresponde al Estado garantizar los medios para ejecutar las respectivas decisiones y sentencias definitivas emitidas por tales autoridades competentes, de manera que se protejan efectivamente los derechos declarados o reconocidos, en el entendido de que una sentencia con carácter de cosa juzgada otorga certeza sobre el derecho o controversia discutida en el caso concreto y, por ende, tiene como uno de sus efectos la obligatoriedad o necesidad de cumplimiento. El proceso debe tender a la materialización de la protección del derecho reconocido en el pronunciamiento judicial mediante la aplicación idónea de dicho pronunciamiento. Por tanto, la efectividad de las sentencias y de las providencias judiciales depende de su ejecución. Lo contrario supone la negación misma del derecho involucrado. ${ }^{110}$

En este sentido, el artículo 25.2.c de la Convención consagra el derecho al cumplimiento, por las autoridades competentes, de toda decisión en que se haya estimado procedente el recurso; ${ }^{111}$ la responsabilidad estatal no termina cuando las autoridades competentes emiten una deci-

108 TEDH. Hornsby c. Grecia, párr. 40, 19/3/1997; Scordino c.Italia ( $n^{\circ}$ 1), párr. 196, 29/3/2006; Bourdov c. Rusia, párr. 34 y 37, 7/5/2002; Nikoloudakis c. Grèce, párr. 43- 45; 26/3/2020

109 TEDH. Hornsby c. Grecia, párr. 40, 19/3/1997; Scordino c.Italia (n 1), párr. 196, 29/3/2006.

110 Corte IDH. Pueblo Indígena Kichwa de Sarayaku vs. Ecuador, párr. 263, 27/6/2012; Flores vs. Perú, párr. $123,6 / 3 / 2019$.

111 Corte IDH. Muelle Flores vs. Perú, párr. 124, 6/3/2019 
sión o sentencia, sino que requiere además que el Estado garantice los medios y mecanismos eficaces para ejecutar las decisiones definitivas, de manera que se protejan efectivamente los derechos declarados. La efectividad de las sentencias depende de su ejecución. El proceso debe tender a la materialización de la protección del derecho reconocido en el pronunciamiento judicial mediante la aplicación idónea de dicho pronunciamiento, ${ }^{112}$ incluyendo "la adopción de medidas adecuadas y eficaces de coerción, para que, de ser necesario, las autoridades que dicten las decisiones o sentencias puedan ejecutarlas y con ello lograr la materialización de la protección del derecho reconocido en el pronunciamiento definitivo."113

Adicionalmente - ha dicho- las disposiciones que rigen la independencia del orden jurisdiccional deben estar formuladas de manera idónea para asegurar la puntual ejecución de las sentencias sin que exista interferencia por los otros poderes del Estado y garantizar el carácter vinculante y obligatorio de las decisiones de última instancia. La Corte estima que en un ordenamiento basado sobre el principio del Estado de Derecho todas las autoridades públicas, dentro del marco de su competencia, deben atender las decisiones judiciales, así como dar impulso y ejecución a las mismas sin obstaculizar el sentido y alcance de la decisión ni retrasar indebidamente su ejecución. ${ }^{114}$

Si el deber de cumplimiento y colaboración con la ejecución a que están llamados los sujetos públicos o privados se incumple, el ordenamiento jurídico ha de prever el conjunto de acciones o medidas, en manos del propio órgano jurisdiccional, destinadas a superar estas omisiones, de manera tal que en ningún caso quede frustrada la efectividad de la resolución judicial. Correlativamente, la actividad de ejecución de sus decisiones le impone al órgano jurisdiccional desplegar todos sus poderes con la energía e intensidad suficiente para superar los obstáculos que

112 Corte IDH. Baena Ricardo y otros vs. Panamá, párr. 73, 28/11/2003; Colindres Schonenberg vs. El Salvador, párr.101, 4/2/2019; Muelle Flores vs. Perú, párr. 125, 6/3/2019

113 Corte IDH. Muelle Flores vs. Perú, párr. 128, 6/3/2019

114 Corte IDH. Mejía Idrovo vs. Ecuador, párr. 106, 5/7/2011; Flores vs. Perú, párr. 127, 6/3/2019. 
pudieran oponérsele y debe comprender todo, pero al mismo tiempo solo lo necesario al fin de garantizar el cumplimiento, de suerte que el resultado sea la identidad entre lo ejecutado y lo estatuido. ${ }^{115}$

La ejecución debe ser íntegra, perfecta y no parcial, ${ }^{116}$ y cualquier intervención justificada en la ejecución no puede tener por efecto obstaculizar, invalidar o demorar indebidamente la ejecución, y mucho menos poner en tela de juicio la esencia de la decisión. ${ }^{117}$

En la ejecución íntegra de la sentencia, el respeto a la intangibilidad del fallo, una vez firme es un presupuesto básico. Desde que la resolución judicial que pone fin al conflicto se pronuncia resulta inmodificable para el propio órgano jurisdiccional que la ha pronunciado (cosa juzgada formal) y, una vez que ha adquirido firmeza por haberse agotado los recursos disponibles contra ella (cosa juzgada material), su contenido ha de permanecer invariable -salvo los casos de correcciones o adiciones no sustanciales que permiten las leyes- y por tanto susceptible de ejecución.

La intangibilidad material de la sentencia conduce a la ejecución en correspondencia con todo su contenido, en sus propios términos, para lo cual deberán agotarse todas las cuestiones acordadas y decididas en el mismo o que guarden con él alguna relación de causalidad directa e inmediata. Ello significa que el procedimiento de ejecución no podrá utilizarse ni para reformar lo decidido o introducir cuestiones no contenidas en la sentencia, ni para volver a debatir aspectos ya resueltos en ella con carácter definitivo, ni para extender la ejecución hacia sujetos a los que no se refiere el fallo ni a supuestos a los que la ley no permita extender sus efectos.

Esto se traduce, en definitiva, en que la intangibilidad de la sentencia firme es una garantía del derecho a la tutela judicial que actúa como límite impeditivo de la mutación del fallo fuera de los casos explícitamente señalados en la ley, por lo que les corresponde a los tribunales adoptar las acciones que garanticen la ejecución, aún en el supuesto de que pos-

115 PAREJo (1995), p. 499.

116 TEDH. Matheus c. Francia, párr. 58, 31/3/2005.

117 TEDH. Immobiliaria Saffi c. Italia, párr. 74, 28/7/1999. 
teriormente considerasen que su decisión fue equivocada.

La interpretación y aplicación de la sentencia, más que atenerse al estricto tenor literal, debe atender a su finalidad, debiéndose extraer de ella todas las naturales consecuencias que deriven de la causa petendi, es decir,

«de los hechos debatidos y de los argumentos jurídicos de las partes, que, aunque no pasan literalmente al fallo, como es lógico, sí constituyen base para su admisión o rechazo por el juzgador, y, por ello, fundamento de su fallo, del cual operan como causas determinantes. Lo cual, es obvio, no supone que se puedan ampliar en fase de ejecución de sentencias los términos del debate, o hacerse pretensiones distintas, ampliando indebidamente el contenido de la ejecución». ${ }^{118}$

\subsection{La tutela cautelar}

La duración habitual de cualquier proceso trae aparejado el riesgo de que, en tanto se resuelva definitivamente el fondo de la controversia, se puedan alterar las circunstancias de hecho o de derecho existentes al momento en que se requirió la intervención judicial, al punto de que cuando se produzca la sentencia, ésta no tenga ningún efecto práctico. La llamada tutela provisional o cautelar, constituye un remedio destinado al mantenimiento de las situaciones fácticas y jurídicas existentes en el momento de promoverse el proceso para prevenir el temor (o evitar el riesgo) del daño jurídico a los bienes o derechos en juego, de modo que con ello pueda garantizarse la eficacia práctica de la resolución definitiva. De esta manera -siguiendo la clásica elaboración teórica de CALAMANDREI-, la tutela cautelar ha de fundarse en la existencia un peligro de daño inminente e irreparable a un bien jurídico y la necesidad y urgencia de la intervención del juez. ${ }^{119}$

En circunstancias donde muchos Estados se enfrentan a atrasos considerables en sus sobrecargados sistemas de justicia, llevándolos a pro-

118 TCE. Sentencia No. 148/1989. En similar sentido la No. 219/1994.

119 CalamandRei (1945), p. 45. 
cedimientos excesivamente largos, la decisión de un juez sobre una medida cautelar a menudo será equivalente a una decisión sobre el fondo de la demanda por un periodo de tiempo sustancial, incluso permanentemente en casos excepcionales. En estos casos, la protección cautelar formará parte del derecho a la tutela judicial efectiva en tanto del examen del objeto, naturaleza, propósitos y efectos de la medida cautelar esta pueda "ser considerada efectiva para determinar el derecho civil u obligación en litigio, a pesar del periodo de tiempo en vigencia." ${ }^{20}$

En relación con el ámbito internacional de los derechos humanos, en el sistema europeo la adopción de medidas cautelares deriva de la aplicación del art. $39^{121}$ del reglamento de procedimientos del TEDH. Se trata de medidas de urgencia adoptadas en el marco del desarrollo del procedimiento ante el tribunal, con carácter excepcional, en caso de que los demandantes estuvieren expuestos - en ausencia de tales medidas - a un riesgo real de graves e irreparables daños y que no prejuzgan sus decisiones futuras sobre la admisibilidad o sobre el fondo de los asuntos en cuestión. ${ }^{122}$

EI TEDH ha afirmado que "las medidas provisionales desempeñan un papel vital para evitar situaciones irreversibles que impidan al Tribunal examinar adecuadamente la solicitud y, en su caso, asegurar al solicitante el beneficio práctico y efectivo de los derechos garantizados por la Convención." 123 En la práctica, las medidas cautelares sólo se aplican en ámbitos muy limitados, la mayoría atañen a casos de expulsión y extradición ${ }^{124}$ y consisten, frecuentemente, en suspender la expulsión del demandante o la extradición durante el tiempo del examen de la demanda. ${ }^{125}$

120 TEDH. Micallef c. Malta, párr. 79-86, 15/10/2009.

121 Art. 39. 1. La Sala o, en su caso, el Presidente de la Sección o el Juez de guardia designado de acuerdo con el apartado 4 del presente artículo podrán, ya sea a instancia de parte o de cualquier otra persona interesada, o de oficio, indicar a las partes cualquier medida cautelar que consideren deba ser adoptada en interés de las partes o del buen desarrollo del procedimiento.

122 TEDH (2016), pp. 1-2.

123 TEDH, Mamatkulov y Askarov c. Turquía, párr. 125, 4/02/2005.

124 TEDH, Mamatkulov y Askarov c. Turquía, párr. 104, 4/02/2005.

125 Entre otras: TEDH. Abdollahai c Turquía, 3/11/2009; W.H. c. Suecia, 8/4/2015; F.G. c. Suecia, 23/3/2016 
El régimen de medidas cautelares en el sistema interamericano se regula en el art. 63.2 de la $\mathrm{CADH}$. La Corte IDH ha establecido que en el Derecho Internacional de los Derechos Humanos las medidas provisionales tienen un carácter no sólo cautelar, en el sentido de que preservan una situación jurídica, sino fundamentalmente tutelar, por cuanto protegen derechos humanos, en la medida en que buscan evitar daños irreparables a las personas.

La función cautelar de las medidas provisionales consiste en preservar los derechos en posible riesgo hasta tanto no se resuelva la controversia; su objeto y fin son los de asegurar la integridad y la efectividad de la decisión de fondo, y de esta manera evitar que se lesionen los derechos en litigio, situación que podría hacer inocua o desvirtuar el efecto útil de la decisión final. En cuanto al carácter tutelar, la Corte señala que, siempre y cuando se reúnan los requisitos básicos, las medidas provisionales se transforman en una verdadera garantía jurisdiccional de carácter preventivo, por cuanto protegen derechos humanos, en la medida en que buscan evitar daños irreparables a las personas. ${ }^{126}$

El artículo 63.2 de la CADH establece tres presupuestos básicos que deben concurrir para la adopción de las medidas provisionales:127 extrema gravedad, urgencia y necesidad de evitar daños irreparables a personas. Estas tres condiciones son coexistentes y deben estar presentes en toda situación en la que se solicite la intervención del Tribunal a través de una medida provisional. En relación con el requisito de "extrema gravedad", se refiere a la intensidad más severa de la violación; el carácter "urgente" implica que el riesgo o amenaza involucrados sean inminentes, lo cual requiere que la respuesta para remediarlos sea inmediata y, en cuanto al daño, debe existir una probabilidad razonable de que se materialice y no debe recaer en bienes o intereses jurídicos que puedan ser reparables.

Aunque su adopción se refiere usualmente a casos pendientes ante la

126 Corte IDH: Cuya Lavy y otros respecto de Perú, párr. 4, 12/3/2020.

127 Corte IDH: entre otras: Asunto B. respecto de El Salvador, párr. 6, 29/5/2013; Cuya Lavy y otros respecto de Perú, párr. 4, 12/3/2020 
Corte, esta ha dicho que excepcionalmente, es posible que las ordene, aún cuando no exista propiamente un caso contencioso en el Sistema Interamericano, en situaciones que, prima facie, puedan tener como resultado una afectación grave e inminente de derechos humanos. ${ }^{128}$

\section{Conclusiones}

Como se ha visto, la tutela judicial efectiva -con independencia de las diversas denominaciones con que se recoge en los instrumentos convencionales de derechos humanos y en los ordenamientos jurídicos internos- se ha erigido en una noción clave en el devenir histórico del constitucionalismo contemporáneo y del derecho internacional de los derechos humanos desarrollados a partir en la segunda mitad del siglo XX. Salvando algunas diferencias terminológicas y otras muy específicas en relación con el contenido, la jurisprudencia convencional, tanto del TEDH como de la Corte IDH, y la constitucional de algunos de los tribunales y cortes de Europa y Latinoamericana han coincidido en establecer, en términos generales, como contenido básico y esencial del derecho fundamental a la tutela judicial efectiva en materia no penal, un conjunto de derechos y garantías concretas, interdependientes unos de otras y que consisten en:

- el derecho a acceder a un juez o tribunal para solicitar la tutela de una situación subjetiva, que implica tanto la posibilidad de deducir las pretensiones como que éstas puedan ser examinadas en cuanto al fondo; considerándose contrarias a este derecho la imposición de costes excesivos, plazos inadecuados, interpretaciones formalistas de la ley $u$ otros obstáculos procesales que dificulten o impidan plantear la controversia;

- derecho a un juez independiente, imparcial y predeterminado por la ley; lo cual requiere el establecimiento de reglas, particularmente en

128 Corte IDH, Unidad de Internación Socioeducativa respecto de Brasil, Cons. 6to, 25/2/2001; Guerrero Larez respecto de Venezuela, Cons. 8vo; 17/11/2009; Asunto B. respecto de El Salvador, párr. 4, 29/5/2013 
lo que respecta a la composición del órgano judicial, nombramiento, cese, competencia, motivos de abstención o rechazo, a fin de descartar cualquier duda razonable en cuanto a su impermeabilidad a los factores externos y su neutralidad con respecto a los intereses que debe juzgar.

- derecho a un proceso con garantías mínimas tendentes a asegurar un resultado justo y que incluye el derecho a la defensa técnica, a la igualdad de oportunidades, la equidad procesal, la celeridad y la utilización de los medios de impugnación previstos en la ley;

- derecho a una resolución de fondo, fundada en Derecho; que incluye la atribución de competencias plenas al órgano judicial para examinar el fondo de la controversia, la exigencia de la motivación de las resoluciones judiciales y su conformidad con el sistema de fuentes establecido;

- derecho a la ejecución, que garantice la consolidación práctica de los derechos o situaciones declaradas en la sentencia;

- derecho a la tutela cautelar para, ante situaciones de riesgo o amenaza inminente de los derechos reclamados, evitar que se produzcan situaciones irreversibles que frustren la eficacia de la tutela.

Las principales diferencias se refieren, fundamentalmente, a la titularidad del derecho a la tutela judicial efectiva respecto de las personas jurídicas, en la que la Corte IDH mantiene una opinión distante a la de su par europea y la gran mayoría de los ordenamientos americanos en el sentido de que aquella las desconoce -salvo excepciones- como sujetos del mismo. De igual forma, tampoco ha existido consenso en el reconocimiento del derecho a la segunda instancia como parte de la noción de tutela judicial efectiva, a diferencia de la materia penal.

Como habrá podido constatarse en este trabajo, a pesar de los grandes avances alcanzados en la delimitación del contenido del derecho fundamental a la tutela judicial efectiva, sigue siendo esta una noción en construcción. En la consolidación de sus presupuestos teóricos seguirá teniendo un papel relevante la labor jurisprudencial y será imprescindible 
continuar fortaleciendo el importante dialogo interinstitucional entre los tribunales internacionales de derechos humanos y las cortes y tribunales nacionales.

\section{Bibliografía}

AtienzA, M. (2005). El Derecho como argumentación. En Jurisdicción y Argumentación en el Estado constitucional de Derecho. México: UNAM.

BARnÉs, J. (1993). La tutela judicial efectiva en la Grundgesetz . En J. Barnés (Ed.), La Justicia Administrativa en el Derecho Comparado. Madrid: Civitas.

Calamandrei, P. (1945). Introducción al estudio sistemático de las medidas cautelares. Buenos Aires: Bibliográfica Argentina.

Del Real, A. (2020). El derecho a la tutela judicial efectiva. Teoría general. En Garantías de los derechos en el nuevo panorama constitucional cubano (págs. 21-38). Madrid: Dykinson.

Diez-Pıcazo, L. M. (2008). Sistema de Derechos Fundamentales (3ra ed.). Pamplona: Civitas.

FERRAJOLI, L. (2005). El papel de la función judicial en El Estado de Derecho. En Jurisdicción y argumentación en el Estado constitucional de Derecho (págs. 87-105). México: UNAM.

Hamilton, A. (1787). A view of the constitution of the judicial department in relation to he tenure of good behaviour. En M. Lean (Ed.), The Federalist: A collection of essays written in favor of the new consitution, Vol II (págs. 290- 299). New York: Library of Congress of the U.S.

MARCHECO, B. (2017). Fundamentos de la Justicia Administrativa (1era ed.). La Habana: Unijuris.

Montesquieu, B. d. (1906). El Espíritu de las Leyes I (vertido al castellano con notas y observaciones por Siro García del Mazo). Madrid: Hijos de M.G Hernandez.

PAREJO, L. (1995). La ejecución de sentencias en el orden jurisdiccional contencioso- administrativo en el Derecho español. En Primeras Jornadas Internacionales de Derecho Administrativo Allan $R$ Brewer Carías. Caracas: Funeda. 
REMÓN, J. (2018). El derecho fundamental a la tutela judicial efectiva. Caracterización general con especial referencia a la jurisdiccion civil. En Comentarios a la Constitución Española, XL Aniversario (págs. 723736). Madrid: Boletín Oficial del Estado.

SÁEz LARA, C. (2018). Tutela judicial efectiva y proceso de trabajo. En Comnetarios a la Constitución Española, XL Aniversario (págs. 748760). Madrid: Boletín Oficial del Estado.

Tribunal Europeo de Derechos Humanos. (2016). Ficha temática- Medidas cautelares. Estrasburgo: Consejo de Europa.

Tribunal Europeo de Derechos Humanos, Consejo de Europa. (2013). Guía del artículo 6 del Convenio - Derecho a un proceso equitativo (parte civil). TEDH.

Waline, M. (1963). Droit Administratif (9na ed.). Paris: Recue Sirey.

\section{Jurisprudencia citada}

Corte Constitucional de Colombia

Sentencia No. C-345/93 de 1993.

Sentencia No. C-934/06, de 2006.

Corte Constitucional del Ecuador

Sentencia, No. 208-17-SEP-CC/ 2017

Corte Constitucional Italiana

Sentencia No. 419/1995 de 8/9/1995.

Corte InTERAmericana de derechos Humanos

Opinión Consultiva OC-9/87, Garantías judiciales en estados de emergencia, 6/10/ 1987.

Unidad de Internación Socioeducativa respecto de Brasil, 25/2/2001.

Tribunal Constitucional vs. Perú, 31/01/2001.

Cantos vs. Argentina, párr. 29, 7/12/2001.

Opinión Consultiva OC-18/03, Condición jurídica y derechos de los migrantes indocumentados, 17/9/2003. 
Baena Ricardo y otros vs. Panamá, 28/11/2003.

Lori Berenson Mejía vs. Perú, 23/6/2005.

Chaparro Álvarez y Lapo Íñiguez vs. Ecuador, 21/11/2007.

Apitz Barbera y otros ("Corte Primera de lo Contencioso Administrativo»)

vs. Venezuela, 5/8/2008.

Valle Jaramillo y otros vs. Colombia, 27/11/2008.

Perozo y otros vs. Venezuela, 28/1/2009.

Kawas Fernández vs. Honduras, 3/4/2009.

Anzualdo Castro vs. Perú, 22/9/2009.

Guerrero Larez respecto de Venezuela, 17/11/2009.

Usón Ramírez vs. Venezuela, 20/11/2009.

Vélez Loor vs. Panamá, párr. 143, 23/11/2010.

Mejía Idrovo vs. Ecuador, 5/7/2011.

Barbani Duarte y otros vs. Uruguay, 13/10/2011.

Forneron e hija vs. Argentina, 27/4/2012.

Pueblo Indígena Kichwa de Sarayaku vs. Ecuador, 27/6/2012.

Asunto B. respecto de El Salvador, 29/5/2013.

Granier y otros (Radio Caracas Televisión) vs. Venezuela, 22/6/2015.

Opinión Consultiva OC-22/16, Titularidad de derechos de las personas jurídicas en el Sistema Interamericano de Derechos Humanos, 26/2/2016.

Maldonado Ordoñez vs. Guatemala, 3/5/2016.

Valencia Hinojosa y otra vs. Ecuador, 105, 29/11/2016.

Colindres Schonenberg vs. El Salvador, 4/02/2019.

Flores vs. Perú, 6/3/2019.

Rico vs. Argentina, 2/09/2019.

Montesino Mejía vs. Ecuador, 27/1/2020.

Cuya Lavy y otros respecto de Perú, 12/3/2020.

Tribunal Constitucional de Chile

Rol No. 1345-09-INC de 25/5/2009.

Rol No. 1865-10-INA de 14/7/2011.

Rol No. 1876-10-INA.de 9/8/2011 
Tribunal Constitucional de España

Sentencia No. 148/1989, 21/9/1989.

Sentencia No. 219/1994, 18/7/1994.

Sentencia No. 214 de 24/11/1999.

Sentencia No. 145/2002, 15/7/2002.

Sentencia No. 38/2003, 14/3/2003.

Sentencia No. 60/2003, 24/3/2003.

Sentencia No. 198/2003, 10/11/2003.

Sentencia No. 105/2006, 3/4/2006.

Sentencia No. 178 de 3/11/2014.

Sentencia No. 149/2015, 6/7/2015.

Sentencia No. 176/2016, 17/10/2016.

Sentencia No. 11/1981, de 8/4/1981

Tribunal Constitucional de Perú

Sentencia No. 4235-2010-PHC/TC, 11/8/2011.

Tribunal Europeo de Derechos Humanos

Comingersoll S.A. c. Portugal, 6/4/200.

Airey c. Irlanda, 9/10/1979.

Pretto y otros c. Italia, 8/12/1983.

Ashingdane c. Reino Unido,28/5/1985.

Poiss c. Austria, 24/3/1987.

Silva Pontes c. Portugal, 7/10/1988.

Langborger c. Suecia, 22/6/1989.

Unión Alimentaria Sanders S.A. c. España, 7/7/1989.

H. c. Francia, 24/10/1989.

Obermeier c. Austria, 28/11/1990.

Vocaturo c. Italia 24/4/1991.

Philis c. Grecia ( $\left.n^{\circ} 1\right)$, 27/8/1991.

De Geouffre de la Pradelle c. Francia, 16/12/1992.

Ruiz-Mateos c. España, 23/6/1993.

Schuler-Zgraggen c. Suiza, 24/6/1993. 
Dombo Beheer B.V. c. Países Bajos, 27/10/1993.

Martins Moreira c. Portugal, 23/3/1994.

Van de Hurk c. Países Bajos, 21/4/1994;

Katte Klitsche de la Grange c. Italia, 19/9/1994.

Fayed c. Reino Unido, 21/9/1994.

Hentrich c. Francia, 22/9/1994.

Beaumartin c. Francia, 24/11/1994.

Ruiz Torija c. España, 9/12/1994

Holy Monasteries c. Grecia, 9 /12/ 1994.

McMichael c. Reino Unido, 24/2/1995.

Procola c. Luxemburgo, 28/9/1995.

Bryan c. Reino Unido, 22/11/1995.

Bellet c. Francia, 4/12/1995,

Vermeulen c. Bélgica, 20/2/1996.

Estima Jorge c. Portugal, 20/8/1996

Terra Woningen B.V. c. Países Bajos, 17/12/1996.

Nideröst-Huber c. Suiza, 18/2/1997.

Hornsby c. Grecia, 19/3/1997.

Robins c. Reino Unido, 23/9/1997.

Helle c. Finlandia, 19/12/1997

Allan Jacobsson c. Suecia, 19/2/1998.

Di Pede c. Italia, 21/4/1998.

Pérez de Rada Cavanilles c. España, 28/10/1998.

Garcia Ruiz c. España, 26, 21/1/1999.

Immobiliaria Saffi c. Italia, 74, 28/7/1999.

Buscemi c. Italia, 16/9/1999.

Humen c. Polonia, 15/10/1999;

McGonnell c. Reino Unido, 8/2/2000.

Miragall Escolano y otros c. España, 25/4/2000 (f)

Frydlender c. Francia, 27/6/2000;

Morel c. Francia, 18/10/2000 (f).

Beer c. Austria, 6/2/2001.

Sotiris et Nikos Koutras ATTEE c. Grecia 16/2/2001 (f)

Wettstein c. Suiza, 21/3/2001 (f). 
Platakou c. Grecia, 5/9/2001 (f).

Hirvisaari v. Finlandia, 27/9/2001.

K.S. c. Finlandia, 12/12/2001.

Crompton c. Reino Unido, 12/3/2002

Bourdov c. Rusia, 7/5/2002.

McVicar c. Reino Unido, 7/08/2002 (f).

P., C. y S. c. Reino Unido, 16/10/2002 (f).

Döry c. Suecia, 12/2/2003.

Beles y otros c. República Checa, 12/2/2003 (f).

Potocka y otros c. Polonia, 27/3/2003.

Kleyn y otros c. Países Bajos, 6/5/2003.

Chevrol c. Francia, 13/5/2003.

Cl Boumois C. Francia, 17/6/2003.

Suominen v. Finland, 1/7/2003.

Pescador Valero c. España, 24/9/2003 (f).

Valovâ y otros C. Eslovaquia, 1/9/2004 (f).

SCP Huglo, Lepage y Asociados, Consejo c. Francia, 1/2/2005.

Mamatkulov y Askarov c. Turquía, 4/02/2005.

Matheus c. Francia, 31/3/2005.

Steel y Morris c. Reino Unido, 15/5/2005 (f).

Mežnarić v. Croatia, 15/7/2005.

Scordino c. Italia ( $\left.n^{\circ} 1\right), 29 / 3 / 2006$;

Martinie c. Francia, 12/4/2006.

Markovic y otros c. Italia, 14/12/2006.

Tüketici Bilincini Geliştirme Derneği c. Turquia, 27/2/ 2007.

Staroszczyk c. Polonia, 22/3/2007.

Švarc y Kavnik c. Eslovenia, 8/5/2007 (f).

Islamic Republic of Iran Shipping Lines c. Turquía, 13/12/2007.

Association Avenir d'Alet c. Francia, 14/2/ 2008.

Micallef c. Malta, 15/10/2009.

Abdollahai c Turquía, 3/11/2009.

Parlov-Tkalcic c. Croacia, 22/12/2009.

Sociedade Agricola Do Ameixial c. Portugal, 11/1/2011.

Klithropiia Ipirou Evva Hellas A.E. c. Grecia, 13/1/2011. 
RTBF c. Bélgica, 15/9/2011 (f).

Stanev c. Bulgaria, 17/1/2012.

Agrokompleks c. Ucrania, 8/3/2012.

Toziczka c. Polonia, 24/7/2012 (f).

W.H. c. Suecia, 8/4/2015.

F.G. c. Suecia, 23/3/2016.

Iglesias Casarrubios y Cantalapiedra Iglesias c. España, 11/10/2016.

Korzeniak c. Polonia, párr. 49, 10/1/2017.

Otegui Mondragón y otros c. España, 6/11/2018.

Raspopović y otros c. Montenegro, 26/3/2020.

Nikoloudakis c. Grèce, 26/3/2020.

Tribunal de Justicia de La Unión EUROPEA

Graham J. Wilson c. Ordre des avocats du barreau de Luxembourg, 19/9/2006. 